\title{
UPCommons
}

Portal del coneixement obert de la UPC

http://upcommons.upc.edu/e-prints

Aquesta és una còpia de la versió author's final draft d'un article publicat a la revista Journal of Constructional Steel Research.

URL d'aquest document a UPCommons E-prints:

http://hdl.handle.net/2117/85184

Article publicat / Published paper:

Arrayago, I., Real, E., (2016) Experimental study on ferritic stainless steel simply supported and continuous beams. Journal of Constructional Steel Research. 119

50-62. Doi: 10.1016/j.jcsr.2015.12.006 


\section{Experimental study on ferritic stainless steel simply supported and continuous beams}

I. Arrayago, E. Real

Department of Civil and Environmental Engineering, Universitat Politècnica de CatalunyaBarcelonaTech, Jordi Girona 1-3, C1 Building (207), Barcelona 08034, Spain

Corresponding author: I. Arrayago Tel: +34 934054156; Fax: +34 934054135, e-mail: itsaso.arrayago@upc.edu

\section{ABSTRACT}

Development of efficient design guidance for stainless steel structures is key for the increased use of this corrosion-resistant material by considering both nonlinear behaviour and strain hardening into resistance prediction expressions, together with the moment redistribution in indeterminate structures. With the aim of analysing the bending moment redistribution capacity of ferritic stainless steel beams, a comprehensive experimental programme on continuous beams is presented. These tests contribute to the assessment of EN1993-1-4 specifications, where no plastic design is allowed, and the classical and new plastic design methods available in the literature for indeterminate stainless steel structures. Four three-point and eight fourpoint bending tests are also reported for the assessment of current codified and revised crosssectional classification limits, analysing the different methods for the prediction of the ultimate bending capacities of ferritic hollow sections. Additional test results reported by other authors in different stainless steel grades and carbon steel are also studied and presented. The analysis indicates that Class 1 cross-sectional classification limits are too optimistic for ferritic stainless steels and further research is needed for the extension of plastic design to these grades, although promising predictions of ultimate loads are obtained for austenitic and lean duplex stainless steels.

\section{HIGHLIGHTS}

- Simply supported bending tests on ferritic stainless steel RHS and SHS are described 
- Continuous beam tests on ferritic stainless steel RHS and SHS are presented

- Different design methods and global plastic analysis are assessed

- Other stainless steel and carbon steel test results are compared

\section{KEYWORDS}

continuous beam tests, Continuous Strength Method, experimental programme, ferritic stainless steel, plastic design, simply supported beam tests

\section{INTRODUCTION}

The increased use of stainless steel elements in construction is the result of its excellent corrosion resistance, good mechanical properties, reduced maintenance requirements and aesthetic appearance. Unfortunately, these appealing characteristics are usually overlooked by the high initial investment requirement if the full life-cycle costs are not considered. Ferritics are therefore important in the spread of stainless steels, as they have a lower associated material cost due to their lower nickel content but yet maintain the rest of desirable stainless steel properties. Therefore, they are cheaper and more price-stable than typical austenitic stainless steel grades, but still present significant corrosion resistance, good ductility, formability and impact resistance as reported by Baddoo and Cashell [1].

Various metallic alloys such as stainless steel have a nonlinear stress-strain relationship, even for low strain values, together with strain hardening and this material response needs to be considered when proposing specific design expressions. European design guidance for stainless steel EN1993-1-4 [2], based on EN1993-1-1 [3] for carbon steel, considers four cross-sectional classes depending on their local buckling susceptibility, and a different resistance is assigned to each class. Nevertheless, no plastic design is allowed for stainless steel elements in EN1993-14 [2] despite their high ductility, which, with the fact that strain hardening effects are not considered when stainless steel structures are designed, leads to overconservative load carrying capacity predictions. 
Although tests on continuous stainless steel beams have already been conducted for austenitic and lean duplex grades with the aim of assessing the moment redistribution capacity of stainless steel beams and the possibility of incorporating plastic design, no experimental results on ferritic stainless steels are available as far as the authors know. Hence, the objective of the continuous beam tests on hollow elements presented in this work is to understand the behaviour of indeterminate ferritic stainless steel structures and the redistribution capacity of these beams. Additionally, a new design method based on the Continuous Strength Method (CSM) for indeterminate structures developed by Gardner et al. [4] and Theofanous et al. [5] is assessed with the conducted tests. Furthermore, three-point and four-point bending tests are also presented for the same cross-sections in order to utilize the experimental results in the analysis of indeterminate structures, and the assessment of the cross-sectional classification limits and design expression is described.

\section{EXPERIMENTAL TESTS}

\subsection{Introduction}

This paper presents a comprehensive experimental investigation on ferritic stainless steel hollow section beams. Simply supported tests were conducted for the determination of the ultimate cross-sectional bending capacity and these results were then utilized in the study of two span continuous beams, where the redistribution capacity of the different beams was investigated. Five different cross-sections were analysed, comprising three Rectangular Hollow Sections (RHS) and two Square Hollow Sections (SHS). The cross-sections were named as follows: S1-80x80x4, S2-60x60x3, S3-80x40x4, S4-120x80x3 and S5-70x50x2, which will be used throughout this paper. All the tests were conducted in the Laboratori de Tecnologia d'Estructures Luis Agulló, in the Department of Construction Engineering at Universitat Politècnica de Catalunya. This experimental programme was developed together with additional compression tests and simply supported bending tests on slender ferritic stainless 
steel RHS and SHS, reported in Bock et al. [6] and complements this study on the flexural behavior of ferritic elements with stockier cross-sections. The specimens were made from grade EN1.4003 ferritic stainless steel and were cold-rolled and seam welded. The chemical composition and tensile properties of the original coil material provided by the manufacturer in the mill certificates have already been reported in [6].

\subsection{Material and initial imperfection characterization}

Cold-forming processes affect cross-sectional behaviour, particularly in the corner regions, with increasing plastic deformations resulting in significant material property enhancement. Hence, the material behaviour of the different cross-sections was characterized by conducting tensile tests on coupons extracted both from the flat (F) and corner (C) regions of the crosssections, as shown in Figure 1.

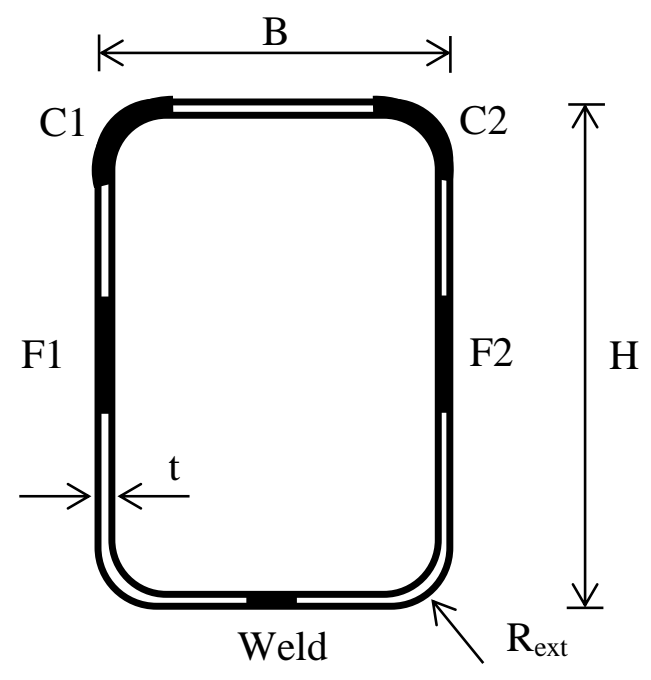

Figure 1. Location of the flat and corner coupons and definition of cross-section symbols.

Two flat specimens and two corner coupons were tested for each cross-section, resulting in a total of 20 tensile tests. The machining and testing of the coupons were conducted in the technical laboratories of Acerinox, in accordance with ISO6892-1 [7]. Coupons were tested under an initial strain rate of $0.00025 \mathrm{~s}^{-1}$ for the determination of the Young's modulus and the yield stress and then increased to $0.008 \mathrm{~s}^{-1}$. Coupons extracted from the corner parts were strips 
with constant cross-sectional area along their entire length, and were extended two times the thickness of the cross-sections into the adjacent flat faces according to [8], since corner properties affect regions beyond the curved portions. The area was calculated by considering the mass of each coupon and the density of the grade EN1.4003 ferritic stainless steel from EN10088 [9]. The flat coupons were machined to the usual dogbone shape, with a nominal width of $15 \mathrm{~mm}$ over the reduced area length, and strains at fracture were measured over the standard gauge length of $5.65 \sqrt{\mathrm{A}_{\mathrm{c}}}$ where $\mathrm{A}_{\mathrm{c}}$ is the cross-sectional area of the coupon.

Averaged key material properties of the flat and corner regions of each cross-section are presented in Table 1, where $\mathrm{E}$ is the Young's modulus, $\sigma_{0.05}$ and $\sigma_{0.2}$ are the proof stresses corresponding to $0.05 \%$ and $0.2 \%$ plastic strains respectively, $\sigma_{\mathrm{u}}$ is the ultimate tensile strength, $\varepsilon_{\mathrm{u}}$ is the corresponding ultimate strain and $\varepsilon_{\mathrm{f}}$ is the strain at fracture. Strain hardening exponents $n$ and $m$ corresponding to the material model proposed by Mirambell and Real [10] are also reported. The material properties have been obtained using a software developed by the authors and described in Real et al. [11] and Arrayago et al. [12].

Table 1. Average tensile test results for the different cross-sections.

\begin{tabular}{ccccccccc}
\hline \hline & $\begin{array}{c}\mathrm{E} \\
{[\mathrm{MPa}]}\end{array}$ & $\begin{array}{c}\sigma_{0.05} \\
{[\mathrm{MPa}]}\end{array}$ & $\begin{array}{c}\sigma_{0.2} \\
{[\mathrm{MPa}]}\end{array}$ & $\begin{array}{c}\sigma_{\mathrm{u}} \\
{[\mathrm{MPa}]}\end{array}$ & $\begin{array}{c}\varepsilon_{\mathrm{u}} \\
{[\%]}\end{array}$ & $\begin{array}{c}\varepsilon_{\mathrm{f}} \\
{[\%]}\end{array}$ & $\mathrm{n}$ & $\mathrm{m}$ \\
\hline $\mathrm{S} 1-\mathrm{F}$ & 173992 & 465 & 521 & 559 & 8.2 & 21.7 & 12.4 & 2.3 \\
$\mathrm{~S} 1-\mathrm{C}$ & 170049 & 441 & 577 & 645 & 1.1 & 7.9 & 5.0 & 5.4 \\
\hline $\mathrm{S} 2-\mathrm{F}$ & 186896 & 433 & 485 & 505 & 6.8 & 20.9 & 12.2 & 2.6 \\
$\mathrm{~S} 2-\mathrm{C}$ & 178049 & 459 & 555 & 587 & 1.0 & 10.1 & 7.9 & 5.2 \\
\hline $\mathrm{S} 3-\mathrm{F}$ & 181632 & 467 & 507 & 520 & 3.6 & 21.0 & 16.4 & 2.5 \\
$\mathrm{~S} 3-\mathrm{C}$ & 183684 & 434 & 558 & 601 & 1.0 & 7.0 & 5.9 & 4.5 \\
\hline $\mathrm{S} 4-\mathrm{F}$ & 176704 & 391 & 430 & 490 & 12.6 & 27.1 & 14.6 & 2.3 \\
$\mathrm{~S} 4-\mathrm{C}$ & 194611 & 457 & 540 & 583 & 1.0 & 10.1 & 7.6 & 4.8 \\
\hline $\mathrm{S} 5-\mathrm{F}$ & 179568 & 381 & 418 & 480 & 13.8 & 26.8 & 15.3 & 2.4 \\
$\mathrm{~S} 5-\mathrm{C}$ & 186026 & 466 & 552 & 575 & 1.1 & 6.5 & 8.0 & 4.6 \\
\hline \hline
\end{tabular}

The different behaviour of flat and corner regions of cross-sections can be considered in the analysis of the experimental results by determining the weighted average material properties as 
established by Hradil and Talja [13]. The parameters are weighted according to the area of the considered flat or corner region compared to the total area of the cross-section, assigning the value of the corresponding material parameter to each region. The key weighted average material properties of the different cross-sections presented in this paper are summarized in Table 2.

Table 2. Weighted tensile material properties.

\begin{tabular}{cccccccc}
\hline \hline & $\begin{array}{c}\mathrm{E} \\
{[\mathrm{MPa}]}\end{array}$ & $\begin{array}{c}\sigma_{0.05} \\
{[\mathrm{MPa}]}\end{array}$ & $\begin{array}{c}\sigma_{0.2} \\
{[\mathrm{MPa}]}\end{array}$ & $\begin{array}{c}\sigma_{\mathrm{u}} \\
{[\mathrm{MPa}]}\end{array}$ & $\begin{array}{c}\varepsilon_{\mathrm{u}} \\
{[\%]}\end{array}$ & $\mathrm{n}$ & $\mathrm{m}$ \\
\hline \hline S1 & 172615 & 456 & 539 & 587 & 5.8 & 8.8 & 2.6 \\
S2 & 183667 & 442 & 509 & 533 & 4.8 & 11.0 & 3.2 \\
S3 & 182637 & 451 & 529 & 554 & 2.5 & 12.9 & 2.7 \\
S4 & 188482 & 406 & 453 & 509 & 10.0 & 13.8 & 2.6 \\
S5 & 181030 & 400 & 449 & 502 & 10.8 & 14.7 & 2.4 \\
\hline \hline
\end{tabular}

Initial imperfections were determined by placing each specimen on a milling machine and measuring the deviations with a LVDT and recorded using a data acquisition system (see Figure 2). Imperfections of the faces at $90^{\circ}$ and $180^{\circ}$ angles from the weld were measured and amplitudes reported in Table 1 are the average value of the measured maximum values.

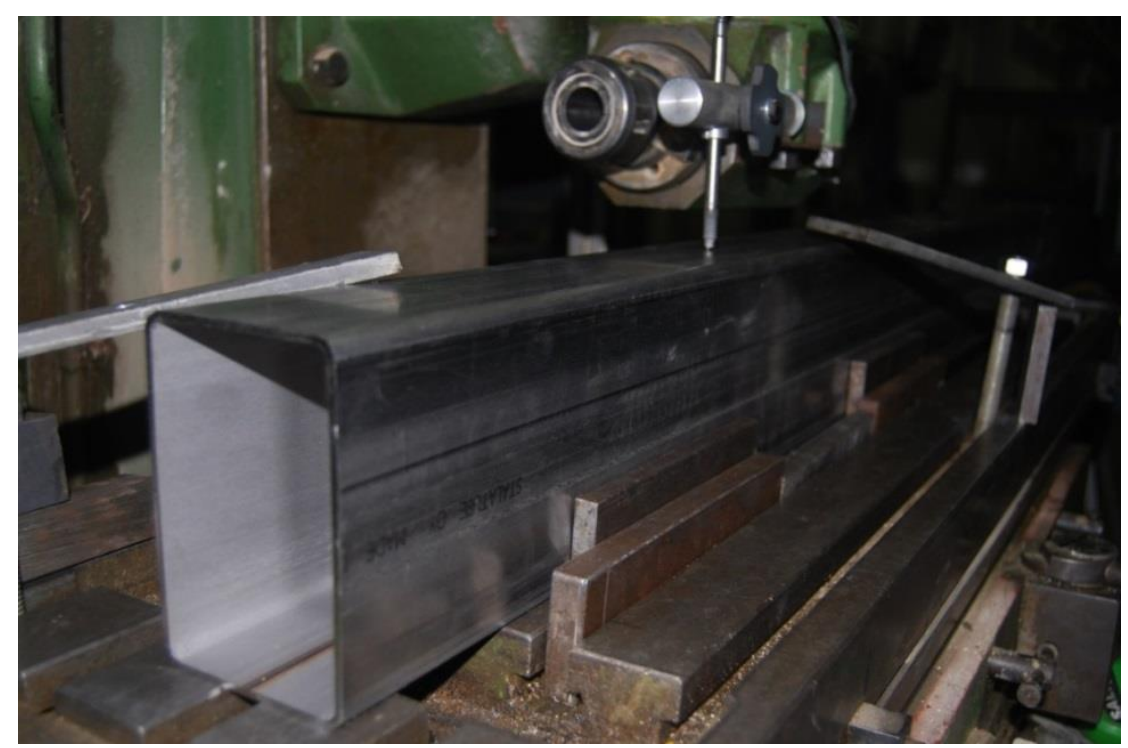

Figure 2. Local imperfection measurement for the $\mathrm{S} 4-\mathrm{Mj}-4 \mathrm{P}$ specimen. 


\subsection{Simply supported tests: three-point and four-point bending tests}

Twelve ferritic stainless steel RHS and SHS simply supported beams were tested under threepoint and four-point bending loading conditions in order to determine their bending moment resistance and rotation capacity and thereby, assess the existing cross-sectional classification limits and design expressions. Eight four-point (labelled as 4P) bending tests were conducted, covering the five studied cross-sections, and considering both major (denoted as $\mathrm{Mj}$ ) and minor (Mi) bending axes for RHS. Four three-point (3P) bending tests were also carried out in this experimental programme, not for all cross-sections and bending axis: the $\mathrm{S} 1, \mathrm{~S} 2, \mathrm{~S} 3-\mathrm{Mj}$ and $\mathrm{S} 4-\mathrm{Mj}$ cross-sections were tested under three-point bending loading conditions. The comparison between different loading conditions will highlight the effect of the bending moment gradient and shear upon the cross-sectional resistance capacity. Although web crippling was not prevented at the loading and support sections in three-point bending tests, these sections were stiffened in four-point bending tests by inserting wooden blocks in order to investigate the influence of stiffening these sections against web buckling caused by local transverse forces.

The average values of the measured key geometrical parameters for the beam specimens are presented in Table 3, where $\mathrm{L}$ is the specimen length, $\mathrm{H}$ is the height, $\mathrm{B}$ is the width, $\mathrm{t}$ is the thickness, $\mathrm{R}_{\mathrm{ext}}$ is the external corner radius, as defined in Figure 1 , and $\mathrm{w}_{0}$ is the maximum amplitude of the measured local imperfections. The class of each cross-section according to both EN1993-1-4 [2] and the revised limits proposed by Gardner and Theofanous [14] for stainless steel cross-sections are also presented.

Table 3. Measured dimensions for the beam specimens.

\begin{tabular}{ccccccccc}
\hline \hline & $\mathrm{L}$ & $\mathrm{H}$ & $\mathrm{B}$ & $\mathrm{t}$ & $\mathrm{R}_{\mathrm{ext}}$ & \multicolumn{2}{c}{$\mathrm{W}_{0}$} & \multicolumn{2}{c}{ Class according to: } \\
& {$[\mathrm{mm}]$} & {$[\mathrm{mm}]$} & {$[\mathrm{mm}]$} & {$[\mathrm{mm}]$} & {$[\mathrm{mm}]$} & {$[\mathrm{mm}]$} & {$[2]$} & {$[14]$} \\
\hline \hline $\mathrm{S} 1-3 \mathrm{P}$ & 1700.0 & 80.0 & 79.9 & 3.8 & 8.0 & 0.069 & Class 3 & Class 1 \\
$\mathrm{S} 2-3 \mathrm{P}$ & 1700.0 & 60.1 & 60.2 & 3.0 & 6.1 & 0.078 & Class 2 & Class 1 \\
\hline
\end{tabular}




\begin{tabular}{ccccccccc}
$\mathrm{S} 3-\mathrm{Mj}-3 \mathrm{P}$ & 1700.0 & 79.9 & 39.9 & 3.9 & 6.6 & 0.078 & Class 1 & Class 1 \\
$\mathrm{S} 4-\mathrm{Mj}-3 \mathrm{P}$ & 1700.0 & 119.8 & 79.9 & 2.6 & 7.0 & 0.060 & Class 4 & Class 3 \\
\hline $\mathrm{S} 1-4 \mathrm{P}$ & 1700.0 & 80.3 & 80.3 & 4.0 & 7.2 & 0.073 & Class 3 & Class 1 \\
$\mathrm{S} 2-4 \mathrm{P}$ & 1700.0 & 60.2 & 60.1 & 2.9 & 6.3 & 0.057 & Class 2 & Class 1 \\
\hline $\mathrm{S} 3-\mathrm{Mj}-4 \mathrm{P}$ & 1700.0 & 79.9 & 39.8 & 3.8 & 7.2 & 0.062 & Class 1 & Class 1 \\
$\mathrm{S} 3-\mathrm{Mi}-4 \mathrm{P}$ & 1700.0 & 79.9 & 39.9 & 3.9 & 6.9 & 0.034 & Class 3 & Class 1 \\
\hline $\mathrm{S} 4-\mathrm{Mj}-4 \mathrm{P}$ & 1700.0 & 119.8 & 79.9 & 2.9 & 7.1 & 0.062 & Class 4 & Class 3 \\
$\mathrm{S} 4-\mathrm{Mi}-4 \mathrm{P}$ & 1700.0 & 119.7 & 80.0 & 2.9 & 7.1 & 0.077 & Class 4 & Class 4 \\
\hline $\mathrm{S} 5-\mathrm{Mj}-4 \mathrm{P}$ & 1700.0 & 70.1 & 49.8 & 1.9 & 4.4 & 0.067 & Class 4 & Class 1 \\
$\mathrm{S} 5-\mathrm{Mi}-4 \mathrm{P}$ & 1700.0 & 70.1 & 49.9 & 2.0 & 4.2 & 0.075 & Class 4 & Class 4 \\
\hline \hline $\mathrm{S} 1-5 \mathrm{P} 1$ & 3200.0 & 80.0 & 79.8 & 4.0 & 8.1 & -- & Class 3 & Class 1 \\
$\mathrm{S} 1-5 \mathrm{P} 2$ & 3200.0 & 79.6 & 79.8 & 4.0 & 8.1 & -- & Class 3 & Class 1 \\
$\mathrm{S} 2-5 \mathrm{P}$ & 3200.5 & 60.2 & 60.2 & 3.1 & 6.4 & -- & Class 2 & Class 1 \\
\hline $\mathrm{S} 3-\mathrm{Mj}-5 \mathrm{P}$ & 3199.5 & 80.1 & 40.0 & 4.1 & 8.6 & -- & Class 1 & Class 1 \\
$\mathrm{S} 3-\mathrm{Mi}-5 \mathrm{P}$ & 3199.5 & 79.9 & 39.8 & 4.0 & 8.1 & -- & Class 3 & Class 1 \\
\hline $\mathrm{S} 4-\mathrm{Mj}-5 \mathrm{P}$ & 3200.0 & 119.4 & 79.9 & 2.9 & 7.5 & -- & Class 4 & Class 3 \\
$\mathrm{S} 4-\mathrm{Mi}-5 \mathrm{P}$ & 3200.0 & 119.6 & 80.5 & 3.0 & 7.4 & -- & Class 4 & Class 4 \\
\hline $\mathrm{S} 5-\mathrm{Mj}-5 \mathrm{P}$ & 3200.5 & 70.1 & 49.9 & 2.0 & 4.3 & -- & Class 4 & Class 1 \\
$\mathrm{S} 5-\mathrm{Mi}-5 \mathrm{P}$ & 3200.0 & 70.0 & 49.7 & 2.0 & 3.8 & -- & Class 4 & Class 4 \\
\hline \hline
\end{tabular}

The total length of the simply supported beams was $1700 \mathrm{~mm}$, with a span length of $1500 \mathrm{~mm}$ for all specimens. All tests were conducted in a $1000 \mathrm{kN}$ capacity MTS hydraulic machine under displacement control, at a testing rate of $2 \mathrm{~mm} / \mathrm{min}$. Data was acquired with the MGCPlus system.

\subsubsection{Three-point bending tests}

Four simply supported beam tests subjected to three-point bending conditions were tested under the setup shown in Figure 3. The load was introduced as a line load through neoprene elements at the midspan and the deflection at the loading point was measured using displacement transducers. The rotation at the loading section was measured using two inclinometers placed at the supports along with load cells to measure the support reactions. The instrumentation also included two strain-gauges, measuring the maximum compressive and tensile strains of the cross-section situated at $60 \mathrm{~mm}$ from the loading point. 


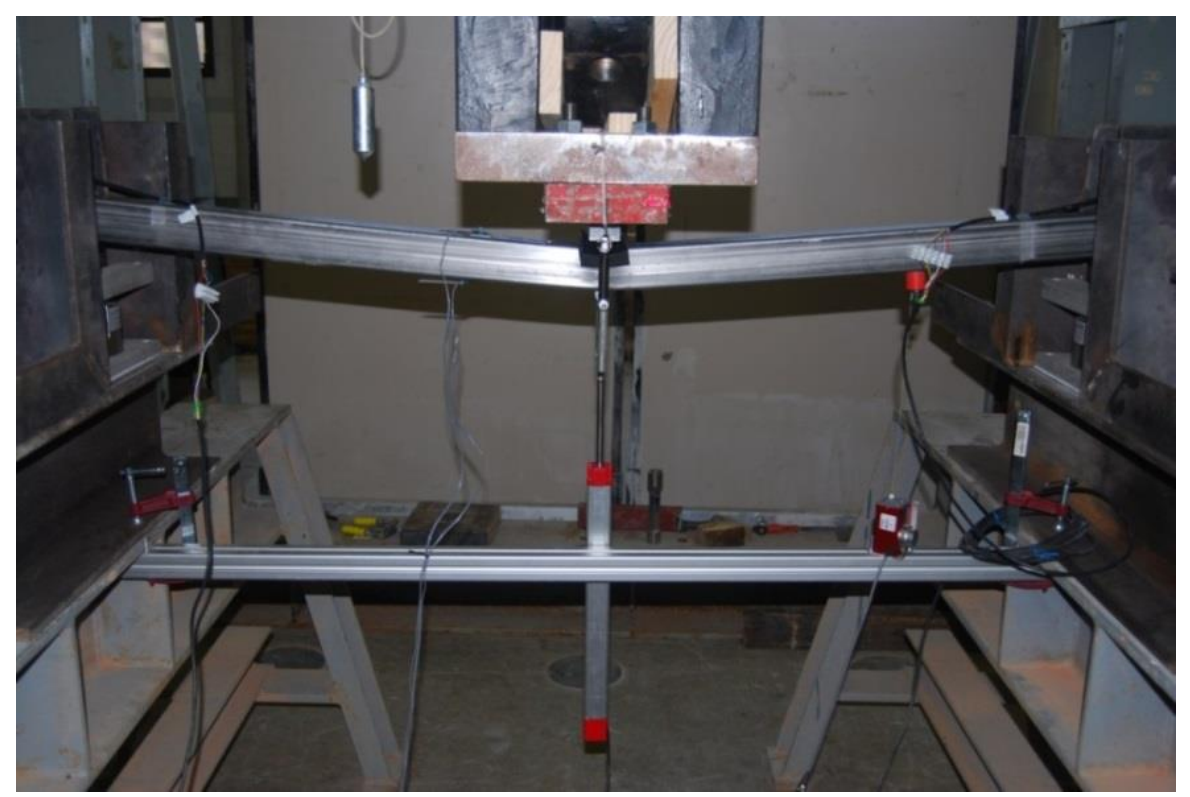

Figure 3. General view of the S2-3P test under three-point bending conditions.

All specimens failed by a combination of buckling of the compressed flange and web crippling at the loading point, since they were not stiffened (see Figure 4a). This needs to be considered when analysing the experimental results as the ultimate bending capacity of the specimens subjected to both bending and web crippling is smaller than for those with stiffened loading sections, where no interaction occurs.

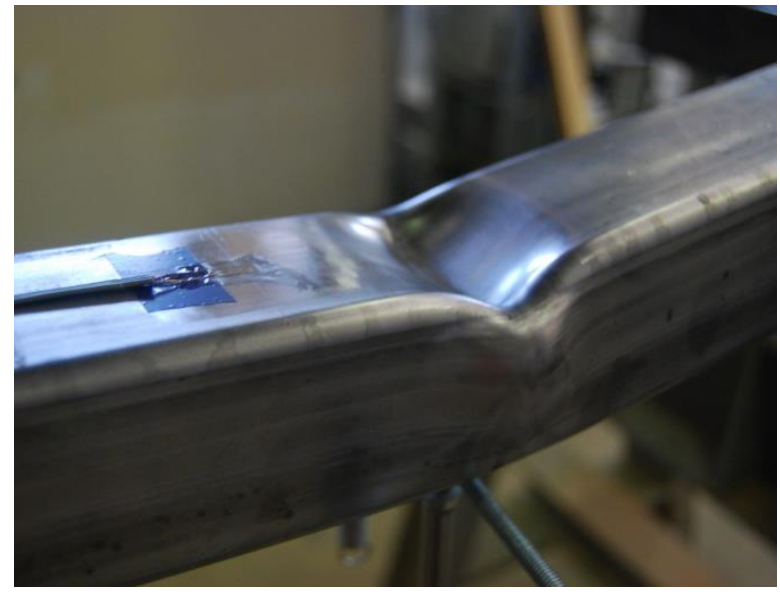

a) Three-point bending loading conditions (no wooden blocks)

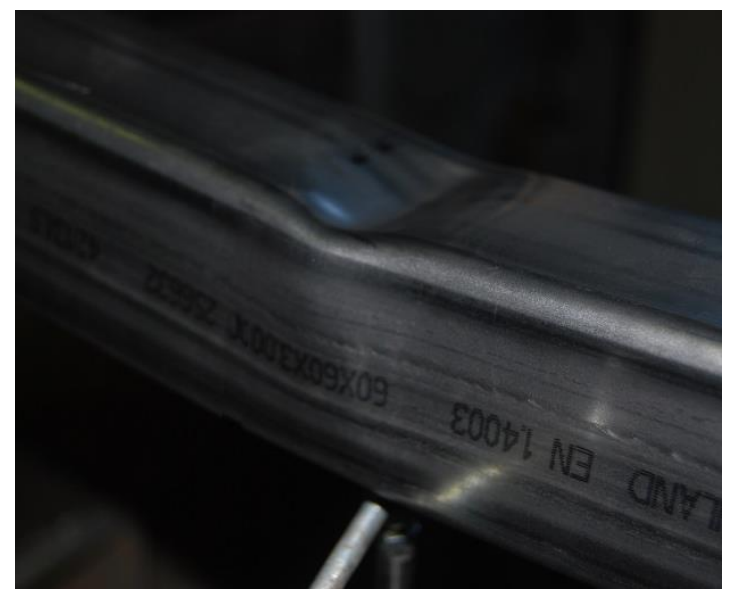

b) Four-point bending loading conditions (wooden blocks)

Figure 4. Detailed view of the failed sections under the load application for the S2 specimens. 
Figure 5 shows the normalized bending moment-rotation curves for the specimens tested under three-point bending conditions. Rotations were calculated as the sum of the measured rotations at the supports and the material and geometric properties described in Tables 2 and 3 were used in $\mathbf{M}_{\mathrm{pl}}$ and $\theta_{\mathrm{pl}}$ calculations. $\mathbf{M}_{\mathrm{pl}}$ is the plastic bending moment capacity and $\theta_{\mathrm{pl}}=\mathbf{M}_{\mathrm{pl}} \mathrm{L} / 2 \mathrm{EI}$, where L is the span length, E is the Young's modulus and I is the relevant second moment of area. As web crippling was not prevented in these specimens, the behaviour of all these beams were similar, showing peak-shape moment-rotation curves as the cross-sections were not capable of rotating while maintaining the achieved ultimate loads, due to web failure.

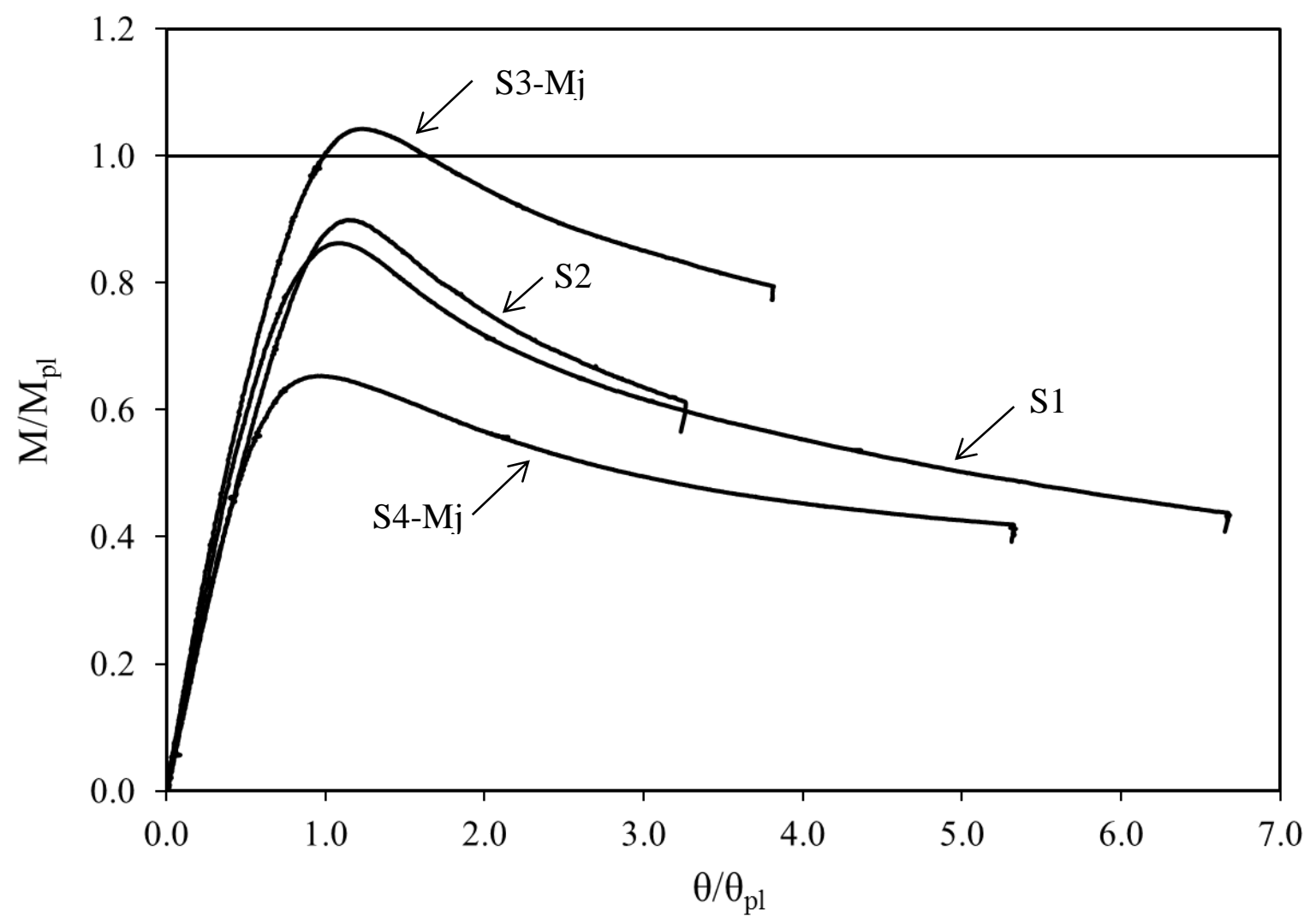

Figure 5. Normalized bending moment-rotation curves for the three-point bending tests.

Three-point bending test results are summarized in Table 4, where the ultimate load $F_{u}$ is reported with the corresponding midspan deflection $d_{u}$, and ultimate bending moment $M_{u}$ calculated from the measured support reactions. The comparison of the experimental bending moment resistances against elastic $\left(\mathrm{M}_{\mathrm{el}}\right)$ and plastic $\left(\mathrm{M}_{\mathrm{pl}}\right)$ bending moment capacities is also 
presented, along with the rotation capacity $R$ provided for those beams showing a $M_{u} / M_{p l}$ ratio greater than 1 . The rotation capacity $\mathrm{R}$ is a measure of rotation between the point where the moment-curvature curves reach the plastic bending capacity $\mathrm{M}_{\mathrm{pl}}$ and the point where the moment falls below $\mathrm{M}_{\mathrm{pl}}$. The graphical definition of this parameter can be found in [5]. For three-point bending tests, the rotation capacity is calculated from $\mathrm{R}=\theta_{\mathrm{u}} / \theta_{\mathrm{pl}}-1$, where $\theta_{\mathrm{u}}$ is the total ultimate rotation at the midspan point corresponding to the ultimate load, calculated as the sum of the rotations at both support sections. $\theta_{\mathrm{pl}}$ is the elastic rotation corresponding to the plastic moment capacity $\mathrm{M}_{\mathrm{pl}}$ in the ascending branch, as previously defined.

Table 4. Summary of the test results for the simply supported beams.

\begin{tabular}{lccccccc}
\hline \hline & $\begin{array}{c}\mathrm{F}_{\mathrm{u}} \\
{[\mathrm{kN}]}\end{array}$ & $\begin{array}{c}\mathrm{d}_{\mathrm{u}} \\
{[\mathrm{mm}]}\end{array}$ & $\begin{array}{c}\mathrm{M}_{\mathrm{u}} \\
{[\mathrm{kNm}]}\end{array}$ & $\mathrm{M}_{\mathrm{u}} / \mathrm{M}_{\mathrm{el}}$ & $\mathrm{M}_{\mathrm{u}} / \mathrm{M}_{\mathrm{pl}}$ & $\mathrm{R}$ & $\begin{array}{c}\text { Experimental } \\
\text { classification }\end{array}$ \\
\hline \hline $\mathrm{S} 1-3 \mathrm{P}$ & 40.4 & 44.7 & 15.2 & 1.06 & 0.86 & -- & Class 3 \\
$\mathrm{S} 2-3 \mathrm{P}$ & 26.4 & 26.4 & 6.2 & 1.11 & 0.90 & -- & Class 2 \\
\hline $\mathrm{S} 3-\mathrm{Mj}-3 \mathrm{P}$ & 30.2 & 30.9 & 11.3 & 1.40 & 1.04 & 0.99 & Class 2 \\
$\mathrm{S} 4-\mathrm{Mj}-3 \mathrm{P}$ & 34.1 & 10.0 & 12.8 & 0.80 & 0.65 & -- & Class 3 \\
\hline $\mathrm{S} 1-4 \mathrm{P}$ & 66.1 & 42.4 & 16.9 & 1.18 & 0.96 & -- & Class 3 \\
$\mathrm{S} 2-4 \mathrm{P}$ & 27.2 & 59.6 & 6.9 & 1.23 & 1.00 & 1.4 & Class 2 \\
\hline $\mathrm{S} 3-\mathrm{Mj}-4 \mathrm{P}$ & 43.2 & 63.8 & 11.0 & 1.36 & 1.02 & 1.8 & Class 2 \\
$\mathrm{S} 3-\mathrm{Mi}-4 \mathrm{P}$ & 26.3 & 104.4 & 6.7 & 1.26 & 1.01 & 2.1 & Class 2 \\
\hline $\mathrm{S} 4-\mathrm{Mj}-4 \mathrm{P}$ & 64.1 & 16.3 & 16.3 & 1.03 & 0.84 & -- & Class 3 \\
$\mathrm{S} 4-\mathrm{Mi}-4 \mathrm{P}$ & 48.6 & 22.5 & 12.4 & 0.97 & 0.83 & -- & Class 4 \\
\hline $\mathrm{S} 5-\mathrm{Mj}-4 \mathrm{P}$ & 19.2 & 48.0 & 4.9 & 1.26 & 1.03 & 1.9 & Class 2 \\
$\mathrm{S} 5-\mathrm{Mi}-4 \mathrm{P}$ & 13.9 & 49.9 & 3.5 & 1.09 & 0.94 & -- & Class 3 \\
\hline \hline
\end{tabular}

\subsubsection{Four-point bending tests}

Eight four-point bending tests on ferritic RHS and SHS were conducted in order to investigate the pure bending response of the cross-sections. The adopted test configuration is presented in Figure 6, where the loads were applied at a distance of 510mm from both supports, being separated by $480 \mathrm{~mm}$. The reactions at both supports were measured in order to verify the symmetry of the system, together with the deflections at the midspan with a string potentiometer and loading points by two displacement transducers for the determination of the 
curvature of the specimens at each load step. Two inclinometers recording end rotations were also placed at the support points.

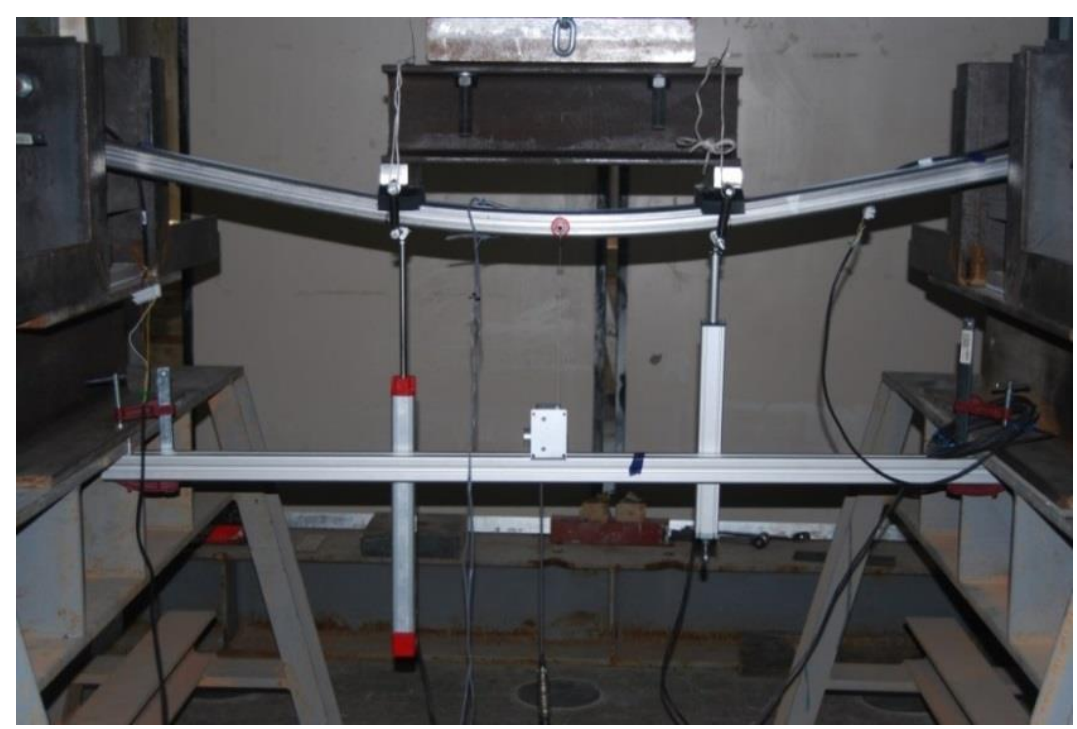

Figure 6. General view of the S3-Mi-4P test under four-point bending conditions.

Strain-gauges were attached to the top and bottom flanges of the cross-sections at a distance of $60 \mathrm{~mm}$ from the midspan section. All specimens failed by local buckling of the compressed flange at the loading points (see Figure 4b) since wooden blocks were inserted at these positions to prevent web crippling.

The key experimental results are summarized in Table 4, where the rotation capacity $\mathrm{R}$ is now determined from $\mathrm{R}=\kappa_{\mathrm{u}} / \kappa_{\mathrm{pl}}-1$, where $\kappa_{\mathrm{u}}$ is the curvature corresponding to the ultimate load and defined as given in Eq. (1), determined using the procedure detailed in [15]. $\kappa_{\mathrm{pl}}$ is the elastic curvature corresponding to $\mathrm{M}_{\mathrm{pl}}$ in the ascending branch, defined as $\kappa_{\mathrm{pl}}=\mathrm{M}_{\mathrm{pl}} / \mathrm{EI}$, $\mathrm{u}_{\mathrm{av}}$ is the average value of the deflections at the loading sections, $\mathrm{u}_{2}$ is the deflection at the midspan section and $\mathrm{L}^{*}$ is the distance between applied loads.

$$
\kappa=\frac{8 \cdot\left(\mathrm{u}_{2}-\mathrm{u}_{\mathrm{av}}\right)}{4 \cdot\left(\mathrm{u}_{2}-\mathrm{u}_{\mathrm{av}}\right)^{2}+\mathrm{L}^{*^{2}}}
$$


Cross-section classification of each specimen, based upon the experimental results, is reported in Table 4. The cross-sections not reaching the elastic bending capacity have been experimentally classified as Class 4 , while those with ultimate bending resistances between elastic and plastic bending capacities have been considered as Class 3. A minimum rotation capacity of $\mathrm{R} \geq 3$ is adopted for guaranteeing the moment redistribution capacity of a carbon steel cross-section and since no specific limit is provided for stainless steel, the same limit is usually adopted [5]. Therefore, the specimens reaching the plastic bending moment capacity but with a rotation capacity lower than 3 have been defined as Class 2, while those with $\mathrm{R} \geq 3$ have been classified as Class 1. As Table 4 demonstrates, a single cross-section can be experimentally adopted as Class 4, S4-Mi, while none of them can be considered Class 1, and the rest are classified either as Class 2 and Class 3.

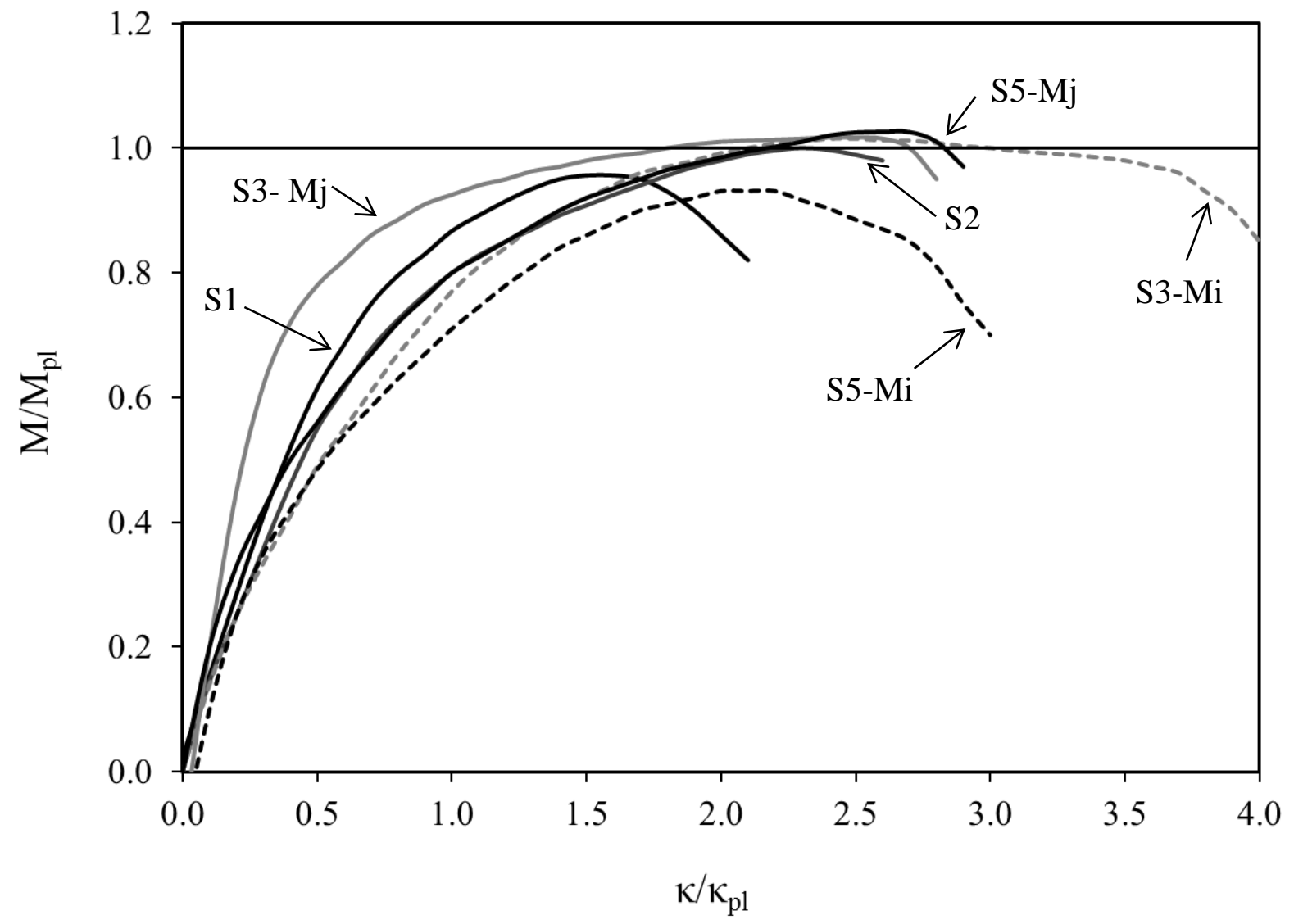

Figure 7. Normalized bending moment-curvature curves for the four-point bending tests. 
The full normalized bending moment-curvature curves are presented in Figure 7 for the fourpoint bending tests, where a different behaviour from that exhibited by the three-point bending specimens can be observed, with greater ductility apparent from a higher load maintained with increasing curvatures. The weighted average material properties presented in Table 2 have been used for the normalization. No curves are presented for section S4 due to data acquisition issues making the curvature calculations impossible, although ultimate loads were recorded.

\subsection{Continuous bending tests: five-point bending tests}

The second part of the experimental programme consisted of nine five-point bending tests (labelled as 5P), which were conducted in order to determine the redistribution capacity of ferritic stainless steel beams. The objective of these tests was to assess whether plastic design, which is not currently allowed in EN1993-1-4 [2], is applicable to ferritic stainless steel coldformed sections. The same cross-sections analysed under simply supported conditions were investigated, with RHS tested in both major and minor bending axes. The measured key geometrical properties of the beams are presented in Table 3.

All specimens tested under the five-point bending configuration had a nominal length of $3200 \mathrm{~mm}$, and were tested over a two span structural configuration. The test setup is shown in Figure 8 with the two loaded $1500 \mathrm{~mm}$ spans, each subjected to a concentrated midspan load. All support reactions were measured using load cells in order to evaluate the reaction redistribution during the tests, midspan deflections were recorded by two displacement transducers and rotations were also measured using inclinometers at the right span outer support and at a distance of $250 \mathrm{~mm}$ from the internal support within the left span. 


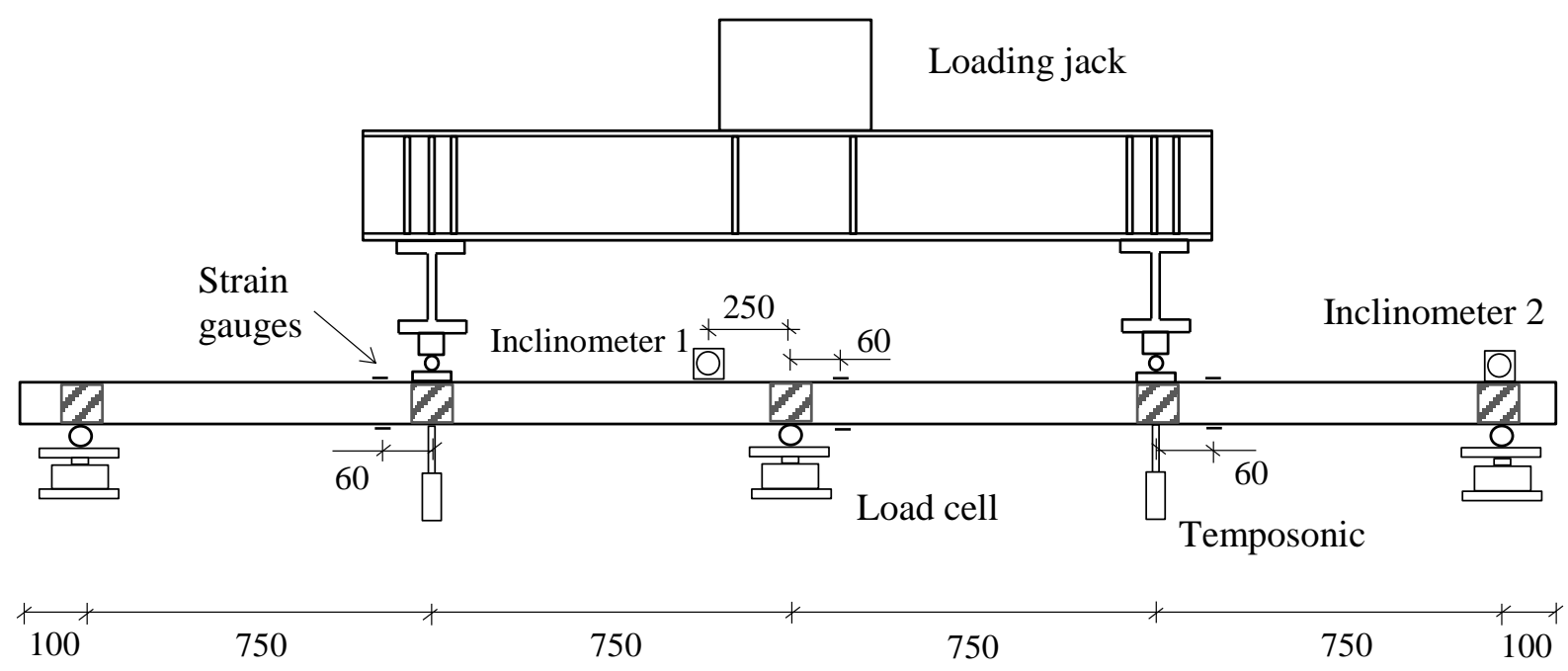

Figure 8. Schematic diagram of the test setup for the five-point bending tests. Dimensions in mm.

Strains at the top and bottom flanges were measured using strain gauges at a distance of $60 \mathrm{~mm}$ from the loading sections and the internal support, and all loading and support points were stiffened with wooden blocks in order to prevent web crippling. The specimens were tested in a $1000 \mathrm{kN}$ MTS hydraulic machine under displacement control at a rate of $2 \mathrm{~mm} / \mathrm{min}$, and failed by local buckling of the compressed flange at the internal support and loading points (see Figure 9).

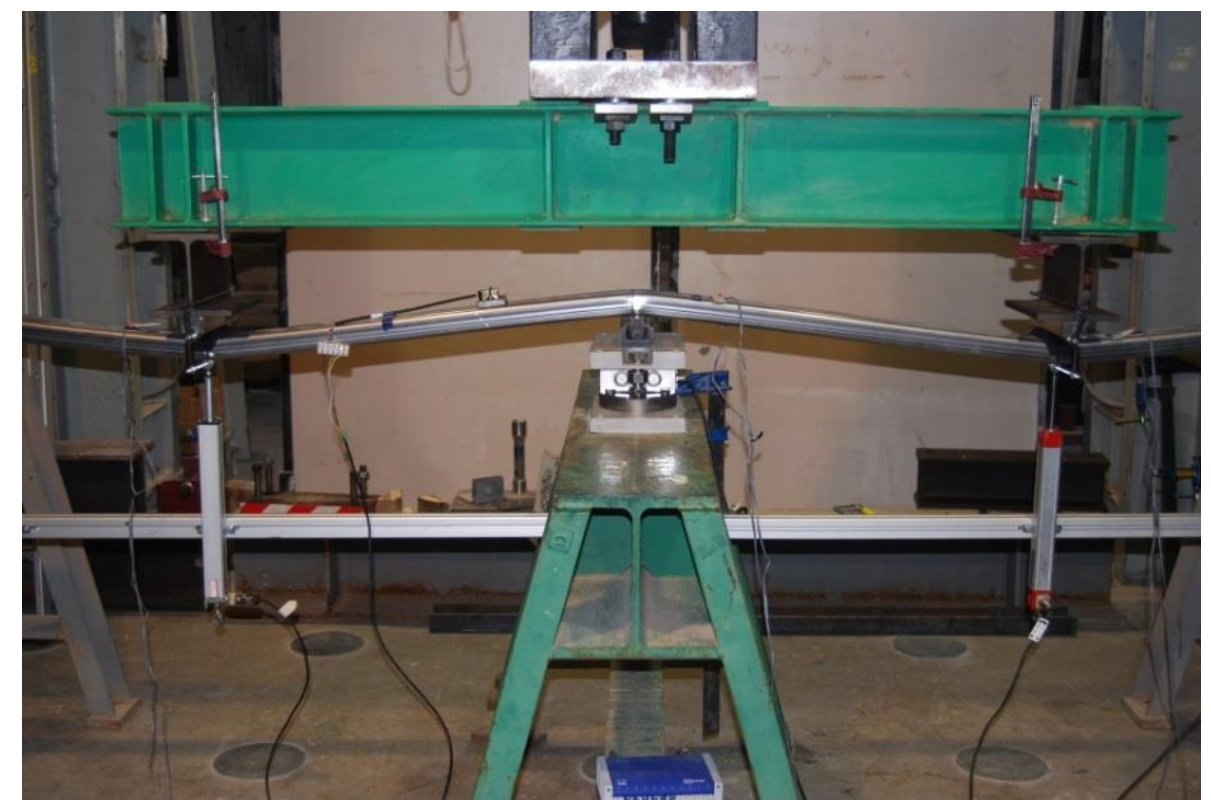

Figure 9. View of the central failed section for the S3-Mi-5P specimen. 
Full load-average midspan deflection curves for the conducted five-point bending tests are presented in Figure 10 and the key test results are reported in Table 5, with the ultimate loads $F_{u}$, corresponding $d_{u}$ midspan deflections, reaction forces at the middle support $R_{u}$ and corresponding rotations at inclinometers 1 and $2, \theta^{1}$ and $\theta^{2}$ (see Figure 8) presented. Continuous bending tests on the $\mathrm{S} 1$ cross-section were repeated in order to demonstrate the reliability of the tests results, with the differences as shown in Figure 10 and Table 5 being minimal.

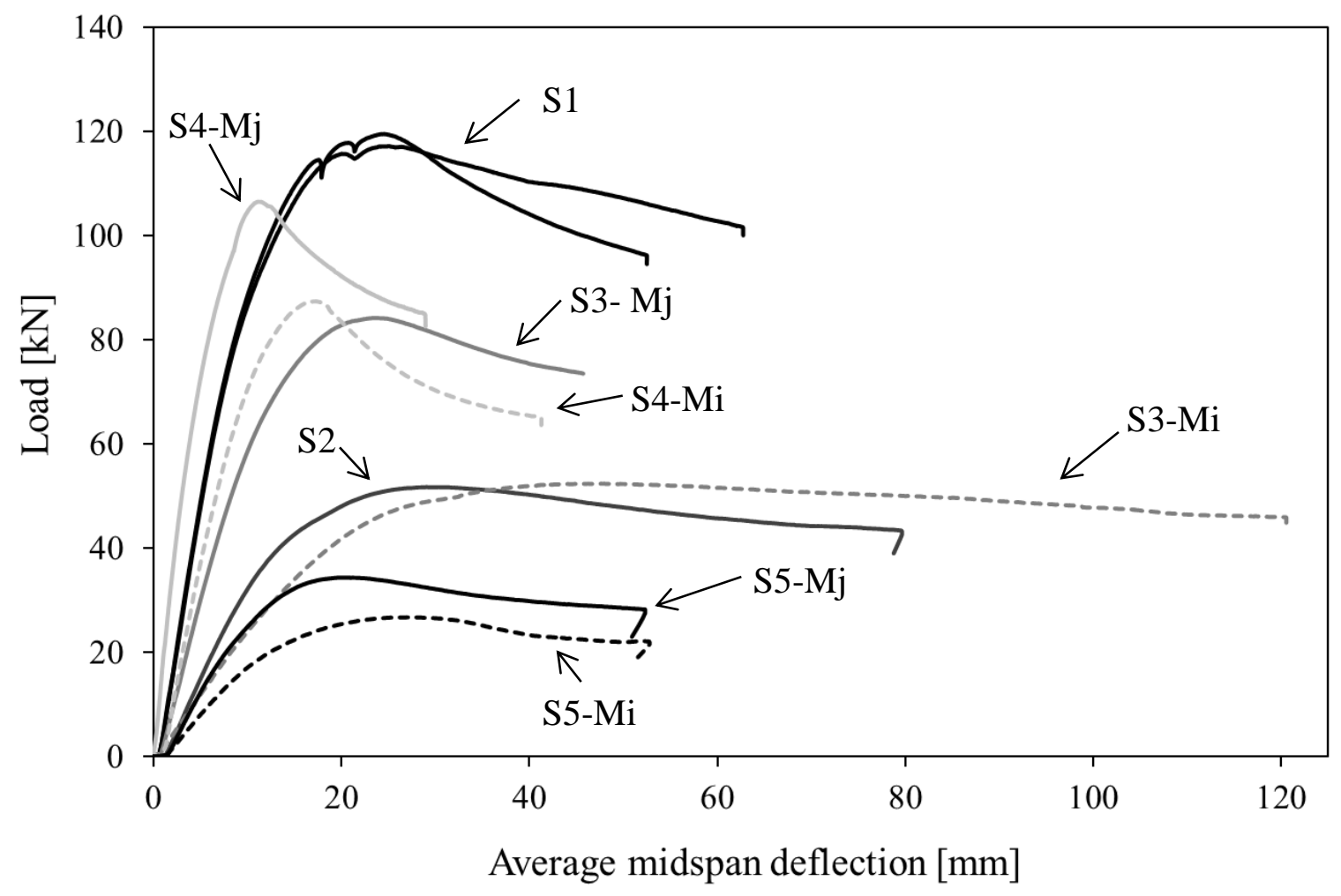

Figure 10. Load-midspan deflection curves for the five-point bending tests.

Table 5. Summary of test results for the five-point bending tests.

\begin{tabular}{cccccc} 
& $\begin{array}{c}\mathrm{F}_{\mathrm{u}} \\
{[\mathrm{kN}]}\end{array}$ & $\begin{array}{c}\mathrm{d}_{\mathrm{u}} \\
{[\mathrm{mm}]}\end{array}$ & $\begin{array}{c}\mathrm{R}_{\mathrm{u}} \\
{[\mathrm{kN}]}\end{array}$ & $\begin{array}{c}\theta_{\mathrm{u}} \\
{[\mathrm{rad}]}\end{array}$ & $\begin{array}{c}\theta_{\mathrm{u}}^{2} \\
{[\mathrm{rad}]}\end{array}$ \\
\hline $\mathrm{S} 1-5 \mathrm{P} 1$ & 117.2 & 25.1 & 77.7 & 0.050 & 0.022 \\
$\mathrm{~S} 1-5 \mathrm{P} 2$ & 119.5 & 24.6 & 79.8 & 0.047 & 0.025 \\
\hline $\mathrm{S} 2-5 \mathrm{P}$ & 51.7 & 29.1 & 34.0 & 0.053 & 0.038 \\
\hline $\mathrm{S} 3-\mathrm{Mj}-5 \mathrm{P}$ & 84.2 & 23.5 & 56.1 & 0.048 & 0.025 \\
$\mathrm{~S} 3-\mathrm{Mi}-5 \mathrm{P}$ & 52.4 & 47.4 & 34.6 & 0.068 & 0.047 \\
\hline $\mathrm{S} 4-\mathrm{Mj}-5 \mathrm{P}$ & 106.5 & 11.4 & 69.5 & 0.022 & 0.010
\end{tabular}




\begin{tabular}{llllll}
$\mathrm{S} 4-\mathrm{Mi}-5 \mathrm{P}$ & 87.4 & 16.7 & 58.7 & 0.029 & 0.012 \\
\hline $\mathrm{S} 5-\mathrm{Mj}-5 \mathrm{P}$ & 34.4 & 20.6 & 22.5 & 0.038 & 0.025 \\
$\mathrm{~S} 5-\mathrm{Mi}-5 \mathrm{P}$ & 26.7 & 27.8 & 17.6 & 0.055 & 0.033 \\
\hline
\end{tabular}

\section{ANALYSIS OF SIMPLY SUPPORTED BEAMS}

\subsection{Introduction}

The experimental results from the ferritic RHS and SHS simply supported beam tests are analysed in this section. After a discussion of the experimental results where the strain gauge results are analysed, the assessment of the different cross-sectional classifications and design approaches is presented. The experimental ultimate bending resistance of each cross-section is compared with the corresponding elastic and plastic bending capacities in order to evaluate cross-sectional class limits, and with the predicted ultimate bending capacities for the assessment of the design methods available in the literature.

\subsection{Discussion of experimental results}

From Table 4 the attained ultimate bending moments $M_{u}$ are higher for the $4 \mathrm{P}$ tests than for the 3P tests, except for S3-Mj specimen due to the stiffening effect introduced by the wooden blocks. As web crippling was prevented in the $4 \mathrm{P}$ tests, no interaction with local transverse loads occurred and higher loads were reached. This difference is greater for those crosssections with slender webs, such as $\mathrm{S} 4-\mathrm{Mj}$, which are more susceptible to web crippling effects. However, for the $\mathrm{S} 3-\mathrm{Mj}$ specimen small differences were observed between the $3 \mathrm{P}$ and $4 \mathrm{P}$ tests, as this cross-section has the largest height-to-width ratio and stocky webs, resulting in a behaviour less influenced by the interaction with web crippling.

The different behaviour exhibited by stocky and slender cross-sections can be better understood from the analysis of the recorded strain gauge data. Figure 11 shows both the load-deflection and load-strain curves for the S2 and S5-Mj specimens tested under 4P loading conditions. The loads and stresses at which the beam does not behave elastically have been identified for both 
specimens, indicating some nonlinearity occurred during the tests. The loads and stresses at which the strain gauges measuring the extreme tensile and compressive strains do not behave identically have also been identified, which indicates local buckling of the compressed flange. In the load-deflection curves stresses have been determined through elastic calculations, while in load-strain curves the stresses corresponding to the strains at which a different behaviour is observed have been considered from the average material curve of each cross-section.

The comparison between these four figures clearly shows the different behaviour exhibited by stocky and slender cross-sections. For the S2 specimen the loss of linearity in Figure 11a can be attributed to the nonlinear stress-strain behaviour, since the local buckling of the compressed flange does not start until higher load levels (see Figure 11b). The load at which the strain gauges diverged was determined when the difference between the compressive and tensile strains reached $1 \%$ of the maximum strain. For the $\mathrm{S} 5-\mathrm{Mj}$ specimen the loss in linearity and the local buckling of the compressed flange occurred at the same load, as shown in Figures 11c and 11d, which indicates that buckling took place while the material was still elastic and the nonlinearity is due to pre-yielding local buckling which is typical of slender elements.

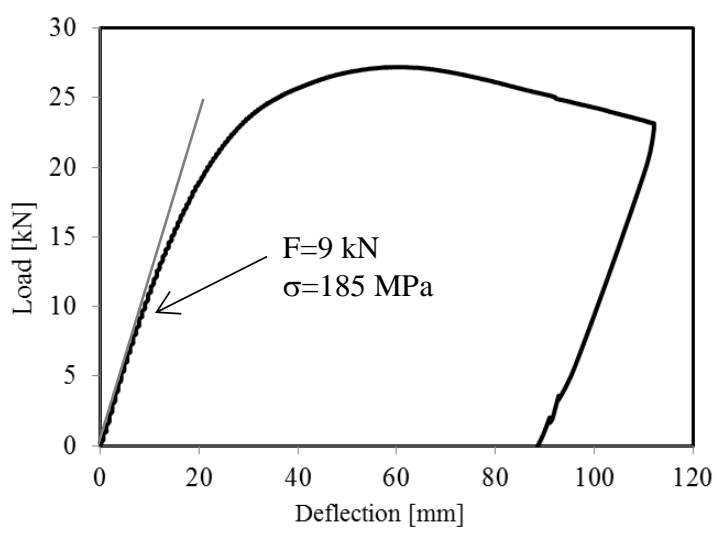

a) Load-deflection curve for $\mathrm{S} 2-4 \mathrm{P}$.

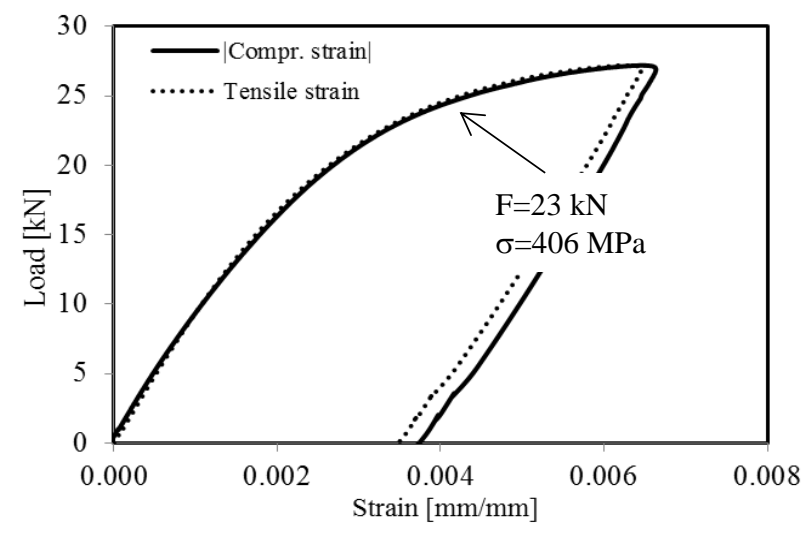

b) Load-strain curve for $\mathrm{S} 2-4 \mathrm{P}$. 


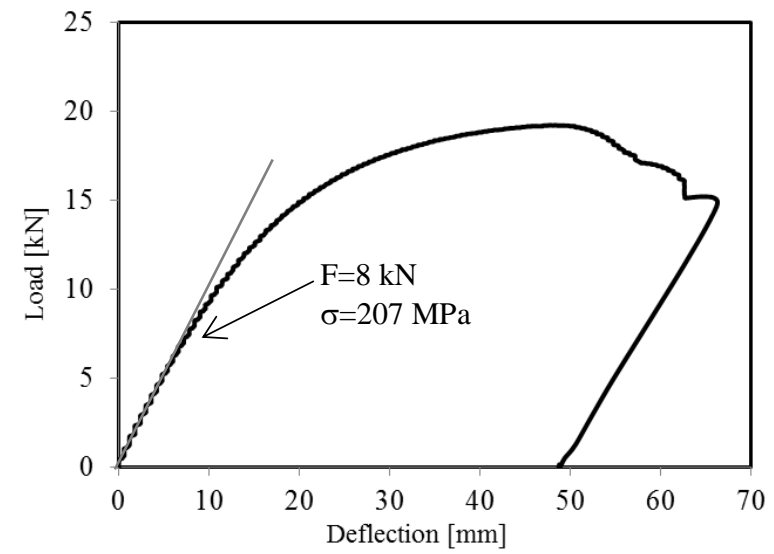

c) Load-deflection curve for $\mathrm{S} 5-\mathrm{Mj}-4 \mathrm{P}$.

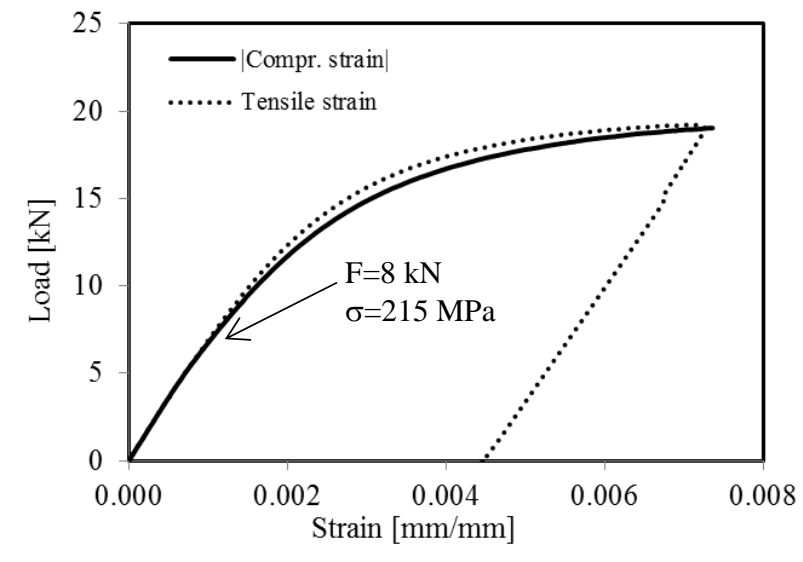

d) Load-strain curve for $\mathrm{S} 5-\mathrm{Mj}-4 \mathrm{P}$.

Figure 11. The $\mathrm{S} 2-4 \mathrm{P}$ (stocky) and $\mathrm{S} 5-\mathrm{Mj}-4 \mathrm{P}$ (slender) cross-section behaviour in bending.

\subsection{Class limit assessment}

The European Standard EN1993-1-4 [2] for the design of structural stainless steel elements accounts for the effect of local buckling through the cross-section classification concept given in EN1993-1-1 [3]. A class is assigned to each cross-section depending upon its susceptibility to local buckling by comparing predetermined limits with the c/ct value of the most slender constituent plate element, considering both geometrical and material properties of the studied element. $\mathrm{c}$ is the width or depth of the relevant part of a cross-section, $\mathrm{t}$ is the element thickness and $\varepsilon$ considers the material properties, defined as $\varepsilon=\left[\left(235 / \sigma_{0.2}\right) \cdot(\mathrm{E} / 210000)\right]^{0.5}$. Class limits are currently codified in EN1993-1-4 [2], although revised limits were proposed by Gardner and

Theofanous [14] for austenitic and duplex stainless steel cross-sections due to overconservatism of the current limits.

As highlighted previously, the ultimate bending moment resistances obtained for the $3 \mathrm{P}$ tests are slightly lower than those reached in the $4 \mathrm{P}$ tests, due to the interaction between bending moment and local transverse forces. Hence, it would be necessary to estimate the bending moment capacity in the absence of web crippling for these $3 \mathrm{P}$ tests in order to make them comparable to the $4 \mathrm{P}$ test results. However, the conservatism when predicting both the web 
crippling resistance and the local force-bending moment interaction would lead to an unconservative estimation of the real bending moment capacity, and consequently the 3P results have not been considered in this class limit assessment.

The assessment of the Class 3 and Class 2 limits is undertaken by comparing the experimental ultimate resistances of the different cross-sections with the corresponding elastic $\left(\mathrm{M}_{\mathrm{el}}\right)$ and plastic $\left(\mathrm{M}_{\mathrm{pl}}\right)$ bending capacities respectively. The normalized experimental ultimate moments calculated using the weighted average material properties are plotted against the cross-sectional slenderness $\mathrm{c} / \mathrm{t} \varepsilon$ and presented in Figure 12 for the assessment of the Class 3 limits for internal elements in compression. Cross-sections that attain their elastic bending moment capacity can be defined as Class 3 or better, and while it can be concluded that EN1993-1-4 [2] limits provide safe results, the revised limits proposed in [14] are more accurate for the tested ferritic RHS and SHS cross-sections.

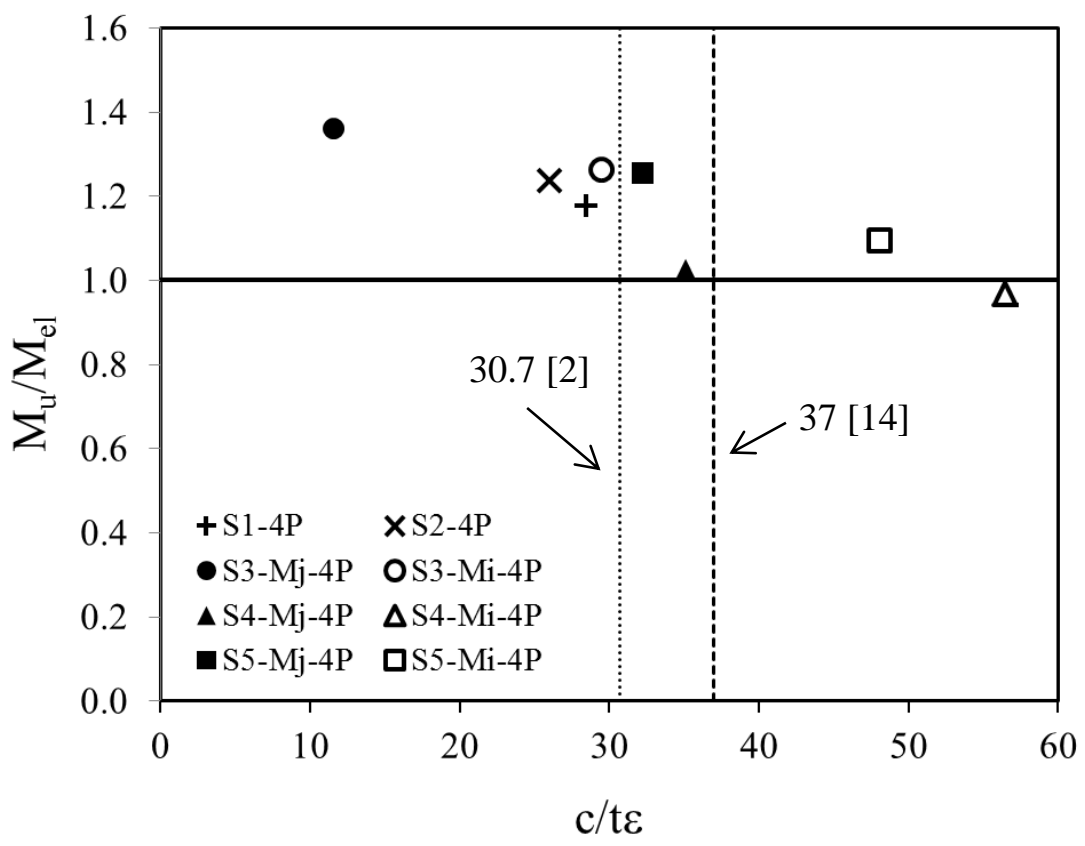

Figure 12. Class 3 limit assessment for the simply supported $4 \mathrm{P}$ beam tests.

The Class 2 limit assessment is shown in Figure 13, where the ultimate bending moment resistances normalized by their corresponding plastic bending capacities are plotted against the 
$\mathrm{c} / \mathrm{t} \varepsilon$ slenderness. It is apparent that adoption of the revised cross-sectional limits proposed in [14] is generally more appropriate although the capacity of the S1 specimen is slightly overpredicted, whereas the current EN1993-1-4 [2] Class 2 limit provides safe but overly conservative results.

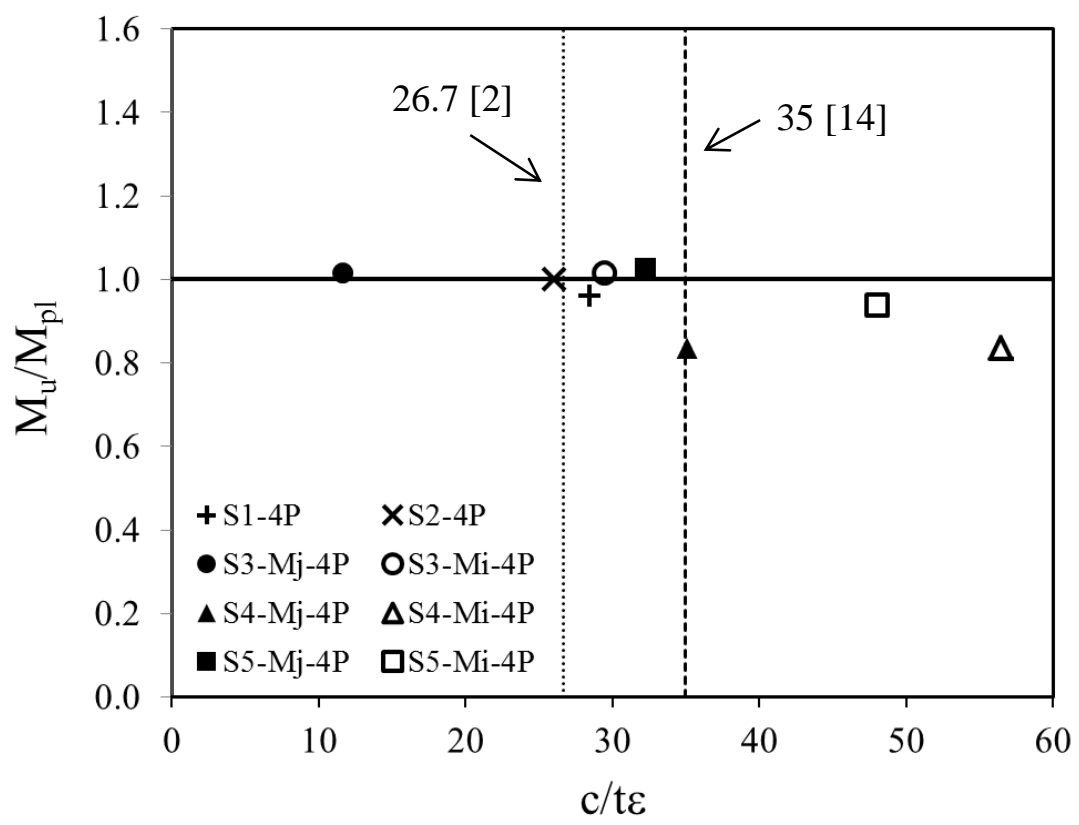

Figure13. Class 2 limit assessment for the simply supported $4 \mathrm{P}$ beam tests.

Finally to assess the Class 1 limit, the rotation capacity $\mathrm{R}$ is plotted against the $\mathrm{c} / \mathrm{t} \varepsilon$ slenderness in Figure 14. As mentioned previously, a minimum rotation capacity of $\mathrm{R} \geq 3$ is typically adopted for stainless steel Class 1 cross-sections since no specific limit is provided. Figure 14 indicates that both Class 1 cross-sectional classification limits appear to be unsafe for the tested specimens, since none of them reach the required rotation limit expected from their c/t $\varepsilon$ slenderness. This can be attributed to the less ductile behaviour of ferritic stainless steel grades compared to austenitic and duplex grades and is in line with existing results reported by Afshan and Gardner [16]. Regardless, the $\mathrm{R} \geq 3$ criterion should be revised when stainless steel crosssections are considered, as the plastic moment capacity of these cross-sections is not clearly defined due to their nonlinear stress-strain behaviour. Consequently alternative criteria based 
on cross-sectional deformation capacity have been proposed for determining whether global plastic design can be considered in [5], which will be analysed in the following sections.

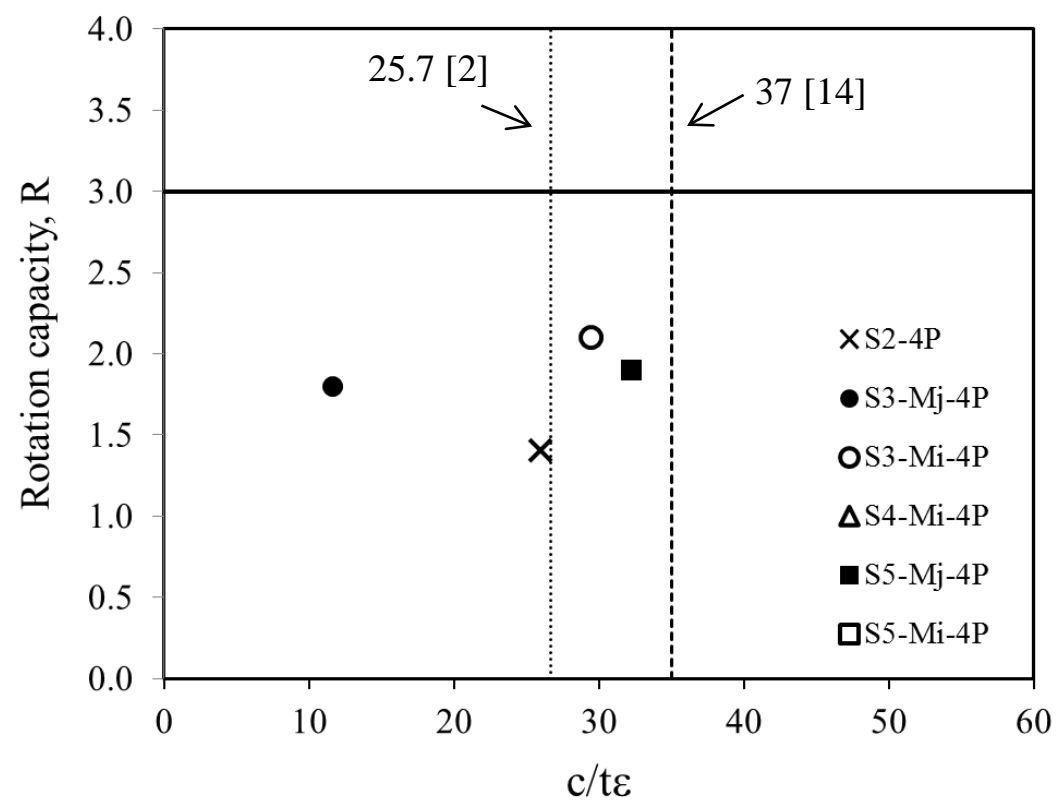

Figure 14. Class 1 limit assessment for the simply supported $4 \mathrm{P}$ beam tests.

\subsection{EN1993-1-4 and CSM assessment for bending}

Existing predictive design expressions for the ultimate bending moment resistance have been compared with the ultimate experimental values. The EN1993-1-4 [2] bending resistance predictions depend on the on the cross-sectional classification as given by Eq. (2).

$\mathrm{M}_{\mathrm{c}, \mathrm{Rk}}=\beta_{\mathrm{W}} \mathrm{W}_{\mathrm{p} 1} \cdot \sigma_{0.2}$

where $\beta_{\mathrm{W}}=1$ is considered for cross-sections classified as Class 1 or 2, for Class 3 sections the elastic bending capacity is determined by considering $\beta_{\mathrm{W}}=\mathrm{W}_{\mathrm{el}} / \mathrm{W}_{\mathrm{pl}}$, and finally, for Class 4 cross-sections, effective properties need to be considered through $\beta_{\mathrm{W}}=\mathrm{W}_{\mathrm{eff}} / \mathrm{W}_{\mathrm{pl}}$, where $\mathrm{W}_{\mathrm{pl}}$ is the plastic modulus, $\mathrm{W}_{\mathrm{el}}$ is the elastic modulus and $\mathrm{W}_{\mathrm{eff}}$ is the effective modulus. Since two different classifications are available for stainless steel cross-sections, both of them will be assessed. 
A new design method based on cross-section deformation capacity, the Continuous Strength Method (CSM), has been developed which aims to offer improved predictions of stocky crosssection resistance by replacing cross-section classification with a continuous deformation based relationship and by considering strain hardening effects. The general description of the method is presented in Afshan and Gardner [17], where all the relevant expressions are provided. This new design method has been extended to cover ferritic stainless steels by Bock et al. [18] with an appropriate ferritic stainless steel material model.

The assessment of the bending resistance prediction expressions codified in EN1993-1-4 [2] assuming both cross-section classification limits is presented in Table 6 , together with capacities predicted by the CSM. $\mathrm{M}_{\mathrm{EN}}$ is the predicted bending resistance considering the current codified classification in [2], $\mathrm{M}_{\mathrm{ENrev}}$ utilizes the revised class limits [14] and $\mathrm{M}_{\mathrm{CSM}}$ is the predicted CSM bending resistance. The current implementation of the CSM does not cover slender cross-sections, so consequently CSM bending resistance predictions are not presented for S4-Mj, S4-Mi and S5-Mi cross-sections. Table 6 demonstrates that Eq. (2) provides safe although very conservative results when the current codified EN 1993-1-4 [2] classification limits are considered, while for the revised limits proposed in [14] more accurate results are obtained, with only the bending capacity of the S1-4P specimen being overestimated. For the CSM predictions the ultimate moment estimations are found to be similar to the experimental results.

Table 6. EN1993-1-4 and CSM assessment for the 4P tests.

\begin{tabular}{cccccccc}
\hline \hline & & \multicolumn{3}{c}{ EN1993-1-4 Eq. (2) } & \multicolumn{2}{c}{ CSM [17,18] } \\
\cline { 3 - 7 } & $\begin{array}{c}\mathrm{M}_{\mathrm{u}} \\
{[\mathrm{kNm}]}\end{array}$ & $\begin{array}{c}\mathrm{M}_{\mathrm{EN}} \\
{[\mathrm{kNm}]}\end{array}$ & $\mathrm{M}_{\mathrm{EN}} / \mathrm{M}_{\mathrm{u}}$ & $\begin{array}{c}\mathrm{M}_{\mathrm{ENrev}} \\
{[\mathrm{kNm}]}\end{array}$ & $\mathrm{M}_{\mathrm{ENrev}} / \mathrm{M}_{\mathrm{u}}$ & $\begin{array}{c}\mathrm{M}_{\mathrm{CSM}} \\
{[\mathrm{kNm}]}\end{array}$ & $\mathrm{M}_{\mathrm{CSM}} / \mathrm{M}_{\mathrm{u}}$ \\
\hline \hline $\mathrm{S} 1-4 \mathrm{P}$ & 16.9 & 14.3 & 0.85 & 17.6 & 1.04 & 17.5 & 1.04 \\
$\mathrm{~S} 2-4 \mathrm{P}$ & 6.9 & 6.9 & 1.00 & 6.9 & 1.00 & 7.0 & 1.00 \\
\hline $\mathrm{S} 3-\mathrm{Mj}-4 \mathrm{P}$ & 11.0 & 10.8 & 0.98 & 10.8 & 0.98 & 11.1 & 1.01 \\
$\mathrm{~S} 3-\mathrm{Mi}-4 \mathrm{P}$ & 6.7 & 5.3 & 0.79 & 6.6 & 0.99 & 6.7 & 0.98 \\
\hline $\mathrm{S} 4-\mathrm{Mj}-4 \mathrm{P}$ & 16.3 & 15.5 & 0.95 & 15.9 & 0.98 & -- & -- \\
$\mathrm{S} 4-\mathrm{Mi}-4 \mathrm{P}$ & 12.4 & 10.0 & 0.81 & 10.4 & 0.84 & -- & -- \\
\hline
\end{tabular}




\begin{tabular}{cccccccc}
$\mathrm{S} 5-\mathrm{Mj}-4 \mathrm{P}$ & 4.9 & 3.9 & 0.79 & 4.8 & 0.97 & 4.6 & 0.93 \\
$\mathrm{~S} 5-\mathrm{Mi}-4 \mathrm{P}$ & 3.5 & 2.8 & 0.79 & 2.9 & 0.82 & -- & -- \\
\hline \hline & & Mean & 0.87 & & 0.95 & & 0.99 \\
& & COV. & 0.107 & & 0.081 & & 0.041 \\
\hline
\end{tabular}

Although the support and loading points were stiffened for four-point bending tests, no wooden blocks were introduced in three-point bending tests where bending moment and web crippling interaction was observed. EN1993-1-4 [2] provisions regarding interaction of local transverse force and bending moment refer to EN1993-1-3 [19] Standard for carbon steel cold-formed sections and it is considered using Eq.(3).

$$
\frac{\mathrm{F}_{\mathrm{Ed}}}{\mathrm{R}_{\mathrm{w}, \mathrm{Rd}}}+\frac{\mathrm{M}_{\mathrm{Ed}}}{\mathrm{M}_{\mathrm{c}, \mathrm{Rd}}} \leq 1.25
$$

where $\mathrm{F}_{\mathrm{Ed}}$ and $\mathrm{M}_{\mathrm{Ed}}$ are the design local transverse force and bending moment respectively, $R_{w, R d}$ is the web crippling resistance and $M_{c, R d}$ is the bending moment resistance. EN1993-1-3 [19] provides several expressions for the determination of the web crippling resistance of crosssections, although Bock et al. [20] proposed a more accurate expression for stainless steel RHS and SHS sections. The local transverse force and bending moment interaction expression given in Eq. (3) have been evaluated by comparing the 3P experimental loads with those predicted by Eq. (4). For this analysis, the bending moment resistances $\mathrm{M}_{\mathrm{u}}$ obtained from the $4 \mathrm{P}$ tests have been considered, together with the two different approaches for the calculation of the web crippling resistance $R_{w, R d}$. $L_{\text {span }}$ refers to the span length, equal to $1500 \mathrm{~mm}$, in the $3 \mathrm{P}$ tests.

$$
\mathrm{F}_{\text {pred }}=1.25\left[\frac{1}{\mathrm{R}_{\mathrm{w}, \mathrm{Rd}}}-\frac{\mathrm{L}_{\mathrm{span}} / 2}{\mathrm{M}_{\mathrm{u}}}\right]^{-1}
$$

Table 7 presents the comparison of the measured ultimate experimental loads $F_{u}$ with those predicted by Eq. (4) and the different approaches of calculating $R_{w, R d}$. This table demonstrates that results obtained for the web crippling resistances given in EN1993-1-3 [19] are overly 
conservative, while the predictions using the Bock et al. [20] formulation can be seen to be substantially improved over the current codified method.

Table 7. Assessment of the local force-bending moment interaction for the 3P tests.

\begin{tabular}{cccc}
\hline \hline & & \multicolumn{2}{c}{$\mathrm{F}_{\text {pred }} / \mathrm{F}_{\mathrm{u}}$} \\
\cline { 3 - 4 } & $\mathrm{F}_{\mathrm{u}}$ & $\mathrm{R}_{\mathrm{w}, \mathrm{Rd}}$ according to & $\mathrm{R}_{\mathrm{w}, \mathrm{Rd}}$ according to \\
& {$[\mathrm{kN}]$} & EN1993-1-3 [19] & Bock et al. [20] \\
\hline \hline $\mathrm{S} 1-3 \mathrm{P}$ & 40.4 & 0.53 & 0.96 \\
$\mathrm{~S} 2-3 \mathrm{P}$ & 26.4 & 0.58 & 0.94 \\
\hline $\mathrm{S} 3-\mathrm{Mj}-3 \mathrm{P}$ & 30.2 & 0.51 & 0.94 \\
$\mathrm{~S} 4-\mathrm{Mj}-3 \mathrm{P}$ & 34.1 & 0.52 & 1.01 \\
\hline \hline & Mean & 0.53 & 0.96 \\
& COV. & 0.059 & 0.035 \\
\hline \hline
\end{tabular}

\section{ANALYSIS OF CONTINUOUS BEAMS}

\subsection{Introduction}

Indeterminate ferritic stainless steel structures are investigated through the conducted nine continuous bending tests, where after the discussion of the test results, the assessment of the different elastic and plastic design methods is presented by comparing the experimental loads with the calculated ultimate resistance predictions.

\subsection{Discussion of experimental results}

The analysis of the experimental results of the S1 and S2 cross-sections based on the reaction and strain gauge measurements is presented in this section in order to illustrate the behaviour of ferritic stainless steel SHS indeterminate beams. For both cross-sections the experimental bending moment at the internal support and span sections, calculated from the measured support reactions, has been plotted against the applied total load as continuous lines in Figures $15 \mathrm{a}$ and $15 \mathrm{c}$, together with the elastically predicted bending moment values as slashed lines. Additionally, the elastic and plastic bending moment capacities are shown, with the experimental bending resistances from the previous simply supported tests. Ultimate bending 
moment values corresponding to the $3 \mathrm{P}$ tests $\mathrm{M}_{\mathrm{u}, 3 \mathrm{P}}$ have been considered since the bending moment distribution in support sections is similar. The measurements obtained from the different strain gauges attached at the internal support sections are also presented (Figures $15 \mathrm{~b}$ and $15 \mathrm{~d}$ ) in order to evaluate the load level at which the compressed flange of the cross-section buckles.

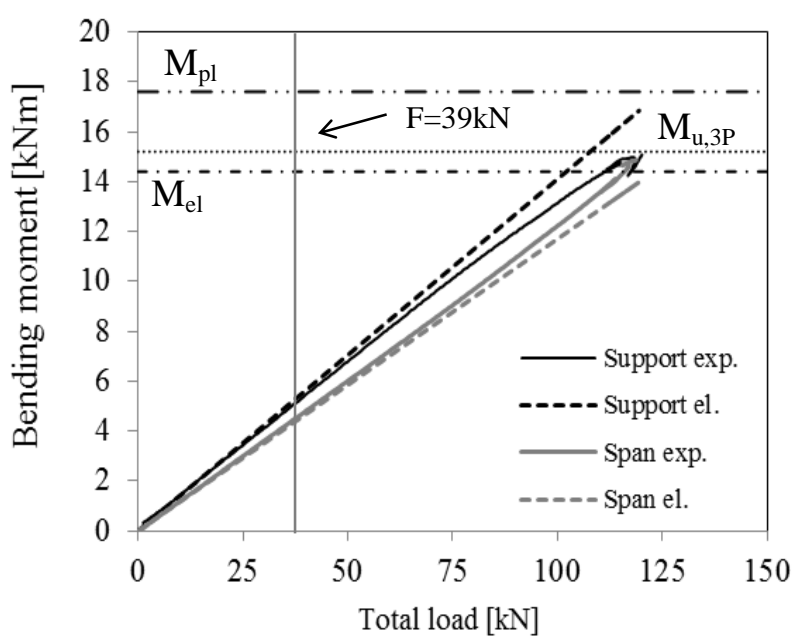

a) Load-bending moment curve for $\mathrm{S} 1-5 \mathrm{P} 2$ at support and span sections.

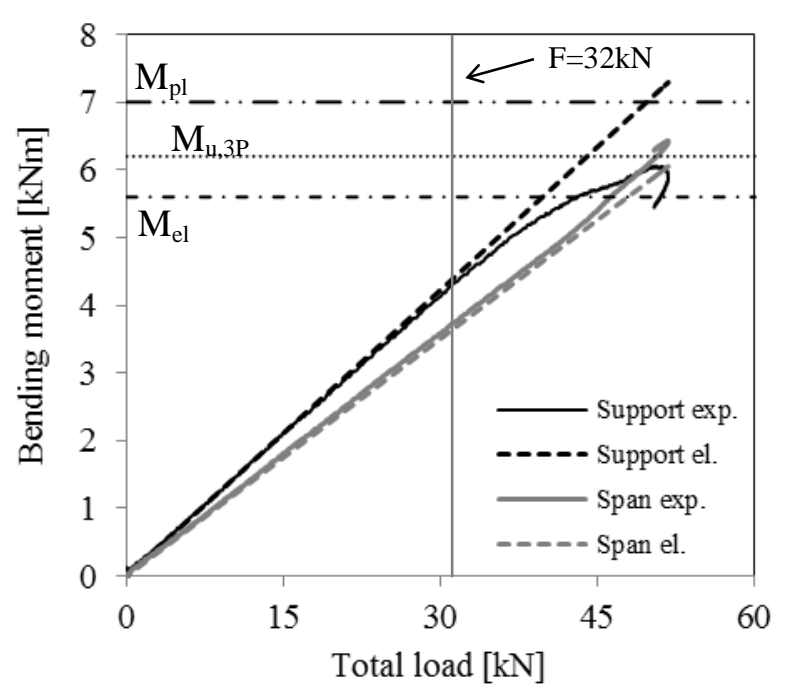

c) Load-bending moment curve for $\mathrm{S} 2-5 \mathrm{P}$ at support and span sections.

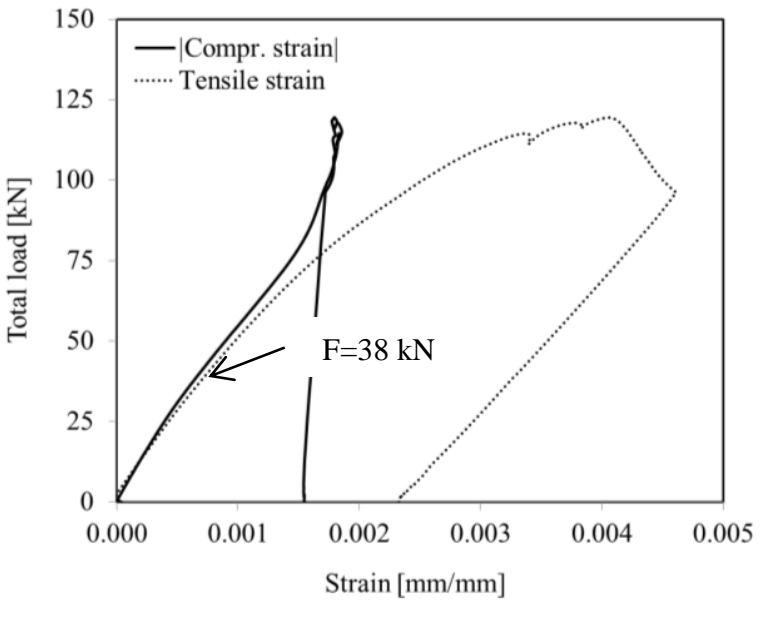

b) Load-strain curve for $\mathrm{S} 1-5 \mathrm{P} 2$ at support section.

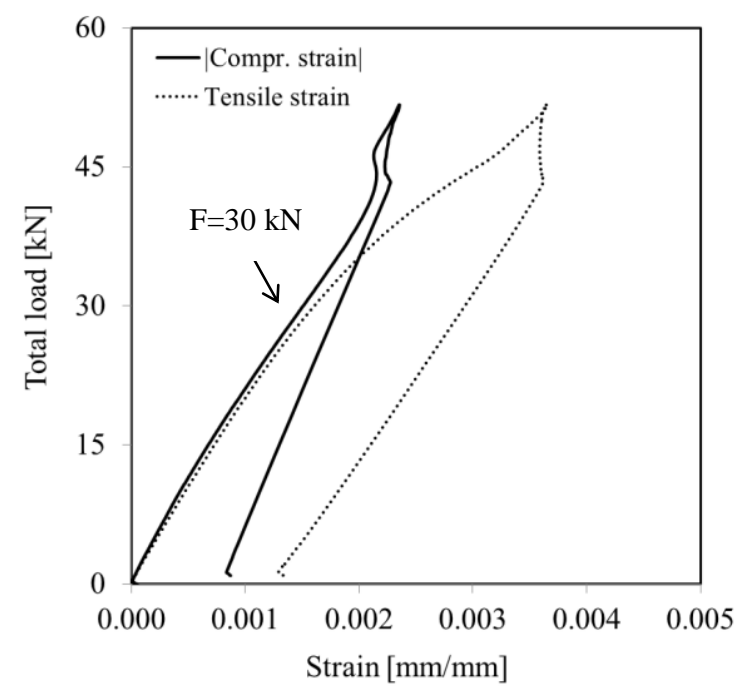

d) Load-strain curve for $\mathrm{S} 2-5 \mathrm{P}$ at support section.

Figure 15. $\mathrm{S} 1-5 \mathrm{P} 2$ and $\mathrm{S} 2-5 \mathrm{P}$ cross-section behaviour as continuous beams. 
Figure 15 shows that for both cross-sections when the load at which the compressive and tensile strains begin to differ the experimental and elastic bending moments also start diverting, indicating the buckling of the compressed flange. Beyond this point, the experimental bending moment at the support increases at a lower rate than the elastic moment while the bending moment at the midspan section increases faster, until the value of the ultimate bending moment for the $3 \mathrm{P}$ tests $\mathrm{M}_{\mathrm{u}, 3 \mathrm{P}}$ is reached and the beams fail.

\subsection{EN1993-1-4 and CSM assessment for indeterminate structures}

EN1993-1-4 [2] states, for two span continuous beams, that the entire beam fails when the first plastic hinge is formed at the central support at the bending capacity predicted by Eq. (2). In order to investigate the applicability of plastic design to ferritic stainless steel structures, the tested beams have also been analysed using EN1993-1-1 [3] by considering a rigid-plastic material response in Class 1 cross-sections.

Theofanous et al. [5] assessed the applicability of the CSM developed by Gardner et al. [4] for stainless steel indeterminate structures. The full CSM cross-sectional resistance is assigned to the critical plastic hinge and allows a degree of strain-hardening for the rest of the hinges. The rotation demand of each hinge is calculated using Eq. (5) where $\theta_{\mathrm{i}}$ is the relative rotation derived from kinematic considerations for the collapse mechanism considered, $\mathrm{h}_{\mathrm{i}}$ is the section height at the location considered and $\left(\varepsilon_{\mathrm{CSM}} / \varepsilon_{\mathrm{y}}\right)_{\mathrm{i}}$ is the corresponding normalized strain ratio at the $i^{\text {th }}$ hinge.

$$
\alpha_{i}=\frac{\theta_{i} \cdot h_{i}}{\left(\varepsilon_{\mathrm{CSM}} / \varepsilon_{\mathrm{y}}\right)_{\mathrm{i}}}
$$

The critical hinge is that showing the largest rotation capacity demand relative to the deformation capacity of the cross-section, and the rest of relative rotation demands are then 
calculated according to Eq. (6), limited to the CSM applicability limits given in Bock et al. [18] for ferritic stainless steel grades due to material ductility requirements in EN1993-1-1 [3] and to avoid overpredictions through the adopted bilinear material models. For the first plastic hinge, the full deformation capacity is exploited, while for subsequent plastic hinges deformations are reduced in proportion to the plastic hinge rotation ratios through the calculated $\varepsilon_{\mathrm{CSM}}$ values. The collapse load is calculated through the virtual work principle as in conventional plastic design.

$$
\left(\frac{\varepsilon_{\mathrm{CSM}}}{\varepsilon_{\mathrm{y}}}\right)_{\mathrm{i}}=\frac{\alpha_{\mathrm{i}}}{\alpha_{\text {crit }}}\left(\frac{\varepsilon_{\mathrm{CSM}}}{\varepsilon_{\mathrm{y}}}\right)_{\text {crit }} \leq\left(\frac{\varepsilon_{\mathrm{CSM}}}{\varepsilon_{\mathrm{y}}}\right)_{\mathrm{i}, \text { limit }}
$$

Sufficient deformation capacity for moment redistribution to occur is usually guaranteed by ensuring a rotation capacity of $\mathrm{R} \geq 3$. However, as previously highlighted, this criterion should be revised when considering stainless steels as the plastic moment capacity of these crosssections is not clear. Gardner et al. [4] proposed a new criterion based on deformation capacity in order to guarantee that a cross-section is capable of moment redistribution in indeterminate structures with a minimum value of $\varepsilon_{\mathrm{CSM}} / \varepsilon_{\mathrm{y}}=3$ for I-sections and 3.6 for box sections, where $\varepsilon_{\mathrm{CSM}}$ is the strain calculated according to the CSM and $\varepsilon_{\mathrm{y}}$ is the elastic strain for the $0.2 \%$ proof stress.

The assessment of the different design methods is reported in Table 8 by providing the predicted collapse loads determined assuming elastic calculations normalized by the experimental ultimate loads. $F_{h 1}$ is the load at which the first plastic hinge is formed at the central support, determined with the bending moment capacity calculated from Eq. (2) for both

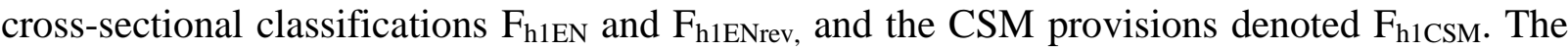
ultimate load predictions tend to slightly overpredict some of the experimental loads when the revised classification or the CSM are considered, while EN1993-1-4 [2] provides conservative but safe results. Note that the considerable differences between $\mathrm{F}_{\mathrm{h} 1 \mathrm{EN}} / \mathrm{F}_{\mathrm{u}}$ and $\mathrm{F}_{\mathrm{h} 1 \mathrm{EN}, \mathrm{rev}} / \mathrm{F}_{\mathrm{u}}$ ratios 
in Table 8, particularly for the S1 and S3-Mi cross-sections, are due to the different Class 3 and 1 limits respectively. This causes the load predictions to be substantially different as the codified classification in [2] assigns the elastic bending moment capacity $\mathrm{M}_{\mathrm{el}}$ to these crosssections while the revised limits in [14] allow for the plastic moment capacity $\mathrm{M}_{\mathrm{pl}}$ to reach.

Table 8. Assessment of the existing design methods based on an elastic analysis and allowing for plastic design for continuous beams.

\begin{tabular}{|c|c|c|c|c|c|c|c|c|}
\hline \multirow{3}{*}{ Section } & \multicolumn{6}{|c|}{ EN1993-1-4 } & \multirow{2}{*}{\multicolumn{2}{|c|}{ CSM }} \\
\hline & \multicolumn{3}{|c|}{ Classification in [2] } & \multicolumn{3}{|c|}{ Classification in [14] } & & \\
\hline & Class & $\begin{array}{c}\mathrm{F}_{\mathrm{h} 1 \mathrm{EN}} / \\
\mathrm{F}_{\mathrm{u}}\end{array}$ & $\begin{array}{c}\mathrm{F}_{\mathrm{uEN}} \\
/ \mathrm{F}_{\mathrm{u}}\end{array}$ & Class & $\mathrm{F}_{\mathrm{h} 1 \mathrm{ENrev}} / \mathrm{F}_{\mathrm{u}}$ & $\begin{array}{c}\mathrm{F}_{\mathrm{uENrev}} \\
/ \mathrm{F}_{\mathrm{u}} \\
\end{array}$ & $\begin{array}{c}\mathrm{F}_{\mathrm{h} 1 \mathrm{CSM}} / \\
\mathrm{F}_{\mathrm{u}}\end{array}$ & $\begin{array}{c}\mathrm{F}_{\mathrm{uCSM}} / \\
\mathrm{F}_{\mathrm{u}}\end{array}$ \\
\hline $\mathrm{S} 1-5 \mathrm{P} 1$ & 3 & 0.87 & "-- & 1 & 1.06 & 1.20 & 1.07 & 1.20 \\
\hline $\mathrm{S} 1-5 \mathrm{P} 2$ & 3 & 0.85 & -- & 1 & 1.04 & 1.18 & 1.05 & 1.18 \\
\hline $\mathrm{S} 2-5 \mathrm{P}$ & 2 & 0.95 & -- & 1 & 0.95 & 1.08 & 0.97 & 1.09 \\
\hline $\mathrm{S} 3-\mathrm{Mj}-5 \mathrm{P}$ & 1 & 0.92 & 1.04 & 1 & 0.92 & 1.04 & 0.95 & 1.07 \\
\hline $\mathrm{S} 3-\mathrm{Mi}-5 \mathrm{P}$ & 3 & 0.72 & -- & 1 & 0.91 & 1.03 & 0.91 & 1.03 \\
\hline $\mathrm{S} 4-\mathrm{Mj}-5 \mathrm{P}$ & 4 & 1.04 & -- & 3 & 1.06 & -- & -- & -- \\
\hline $\mathrm{S} 4-\mathrm{Mi}-5 \mathrm{P}$ & 4 & 0.81 & -- & 4 & 0.85 & -- & -- & -- \\
\hline $\mathrm{S} 5-\mathrm{Mj}-5 \mathrm{P}$ & 4 & 0.80 & -- & 1 & 0.98 & 1.11 & 0.94 & -- \\
\hline $\mathrm{S} 5-\mathrm{Mi}-5 \mathrm{P}$ & 4 & 0.74 & -- & 4 & 0.77 & -- & -- & -- \\
\hline & Mean & 0.86 & 1.04 & & 0.95 & 101.11 & 0.98 & 101.11 \\
\hline & COV. & 0.119 & -- & & 0.105 & 0.064 & 0.064 & 0.066 \\
\hline
\end{tabular}

Table 8 also presents the predicted load normalized by the experimental ultimate load for plastic design for the tested specimens classified as Class $1, \mathrm{~F}_{\mathrm{uEN}} / \mathrm{F}_{\mathrm{u}}$ and $\mathrm{F}_{\mathrm{uENrev}} / \mathrm{F}_{\mathrm{u}}$ and for the CSM denoted $\mathrm{F}_{\mathrm{uCSM}} / \mathrm{F}_{\mathrm{u}}$. It should be noted that for the tests presented in this paper the rotation capacity demand on the three plastic hinges calculated from Eq. (5) is the same, allowing the full CSM resistance across all hinges. Therefore this method is equivalent to considering plastic design with a bending moment capacity determined according to CSM instead of $\mathrm{M}_{\mathrm{pl}}$.

Figure 16 presents the measured experimental load-end rotation curves for continuous beam tests, where loads have been normalized by the collapse loads determined according to conventional plastic design $\mathrm{F}_{\text {coll }}$. This figure demonstrates that the consideration of plastic design overestimates the capacity of all the tested beams, since none of the cross-sections has 
the sufficient rotation capacity to develop a full plastic mechanism and reach the corresponding collapse load. Therefore the specimens cannot be experimentally considered as Class 1 crosssections. This can also be observed in Table 8, where the collapse loads determined through plastic analysis overestimate the real capacity of all the specimens classified as Class 1 . These results reinforce the conclusions obtained in the Class 1 limit assessment in Section 3.3, highlighting that both analysed classifications provide unsafe Class 1 predictions for coldformed ferritic RHS and SHS.

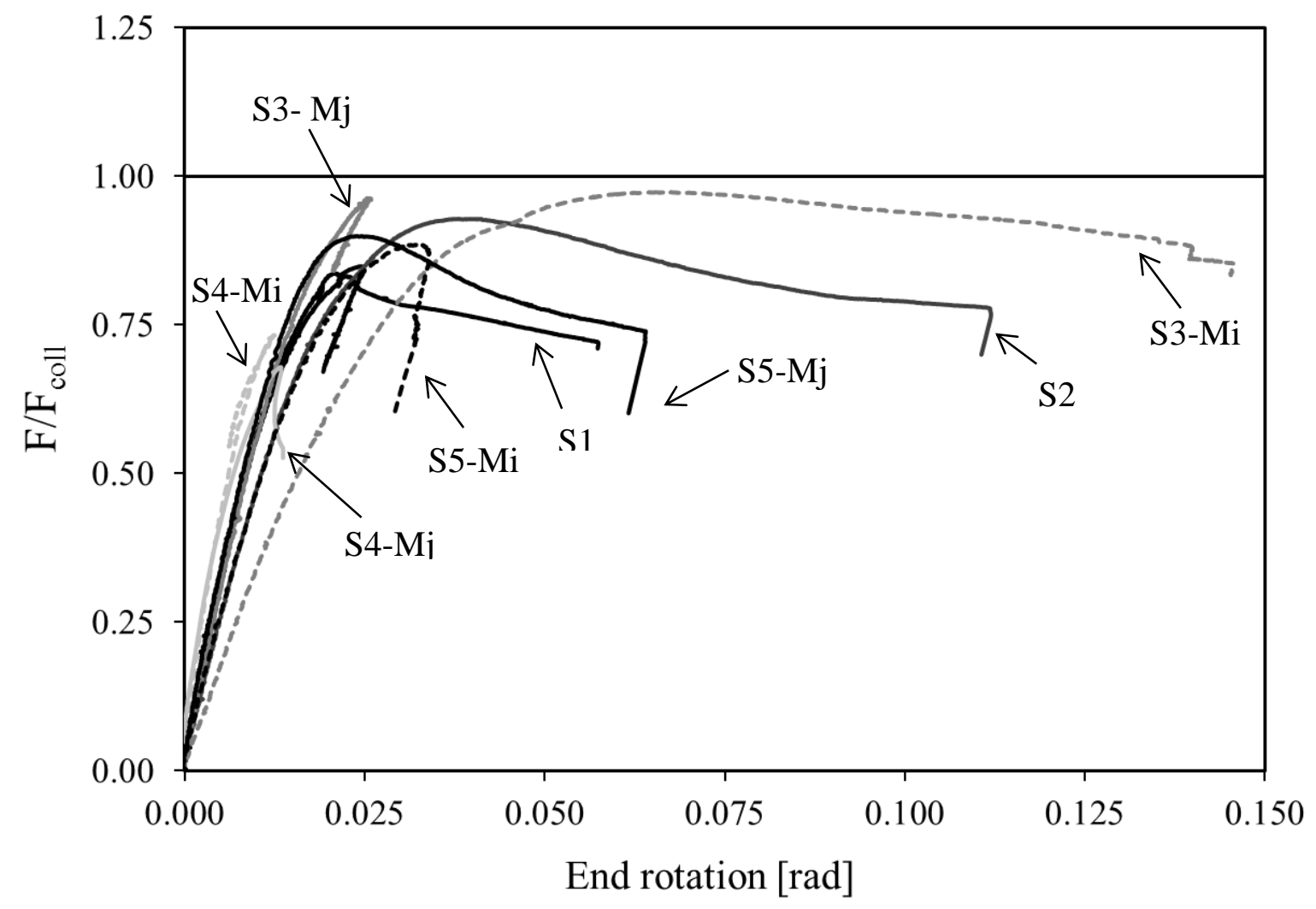

Figure 16. Normalized load-end rotation experimental curves for the continuous beam tests.

The most appropriate predictions of the ultimate capacities of the ferritic RHS continuous beams studied in this paper utilising the design method in EN1993-1-4 [2] are obtained using the revised cross-sectional limits for Classes 2 and 3 proposed by Gardner and Theofanous [14]. These experimental results also highlight that a new Class 1 limit is required, based on deformation capacity criteria, for cold-formed ferritic stainless steel RHS and SHS. The study 
of the applicability of plastic analysis for ferritic stainless steel indeterminate structures would be therefore still open and requires further research involving more stocky specimens and finite element analysis.

\subsection{Additional experimental results from literature}

The test results presented and analysed in this paper have been complemented with additional experimental continuous beam test data collected from the literature in order to provide a general overview of the different design methods and compare the behaviour of ferritic RHS and SHS beams with other cross-sections and different stainless steel grades. Experimental results conducted on carbon steel continuous beams have also been included in the analysis.

Double span tests on austenitic stainless steel grade EN1.4301 continuous RHS and H-section beams were reported by Mirambell and Real [10] and Real and Mirambell [21] under different structural configurations. Tests conducted on austenitic stainless steel EN1.4301/1.4307 RHS and SHS and EN1.4162 lean duplex H-sections by Theofanous et al. [5] have also been included in this study and the carbon steel indeterminate beam results include the RHS continuous beams reported by Gardner et al. [4], Yang et al. [22] and Popov and Willis [23]. Also included are carbon steel indeterminate beam test on $\mathrm{H}$-sections from Driscoll and Beedle [24]. More detailed information of these tests can be found in the original publications.

Table 9 summarizes the assessment of the previously considered design methods for stainless steel and carbon steel indeterminate beams reported in the literature. Both cross-sectional classifications have been considered, that currently codified in EN1993-1-4 [2] and the one proposed by Gardner and Theofanous [14] for stainless steel cross-sections; and that codified in EN1993-1-1 [3] for carbon steel cross-sections. Plastic design has been considered for Class 1 cross-sections, while elastic calculations have been undertaken for the remaining crosssections, with the corresponding moment resistance calculated according to Eq. (2). CSM 
ultimate load predictions for the indeterminate beams have also been considered, with the approach adopted for carbon steel taken from [25].

Table 9. Assessment of existing design methods allowing for plastic design for the additional

\begin{tabular}{|c|c|c|c|c|c|c|c|}
\hline \multirow[t]{2}{*}{ Section } & \multirow[t]{2}{*}{ Grade } & \multicolumn{2}{|c|}{$\begin{array}{l}\text { EN1993-1-4 [2]/ } \\
\text { EN1993-1-1 [3] }\end{array}$} & \multicolumn{2}{|c|}{ Revised limits [14] } & \multirow{2}{*}{$\begin{array}{c}\mathrm{CSM} \\
\mathrm{F}_{\mathrm{uCSM}} / \mathrm{F}_{\mathrm{u}}\end{array}$} & \multirow[t]{2}{*}{ Source } \\
\hline & & Class & $\mathrm{F}_{\mathrm{uEN}} / \mathrm{F}_{\mathrm{u}}$ & Class & $\mathrm{F}_{\mathrm{uENrev}} / \mathrm{F}_{\mathrm{u}}$ & & \\
\hline SHS-80x80x3 & 1.4301 & 4 & 0.78 & 2 & 0.98 & -- & {$[10,21]$} \\
\hline SHS-80x80x3 & 1.4301 & 4 & 0.72 & 2 & 0.91 & -- & {$[10,21]$} \\
\hline RHS-120x 80x3 & 1.4301 & 2 & 0.56 & 1 & 0.71 & 0.75 & {$[10,21]$} \\
\hline RHS-120x80x3 & 1.4301 & 2 & 0.61 & 1 & 0.78 & 0.82 & {$[10,21]$} \\
\hline SHS-50x50x3 & 1.4301 & 1 & 0.75 & 1 & 0.75 & 0.91 & [5] \\
\hline SHS-50x 50x3 & 1.4301 & 1 & 0.76 & 1 & 0.76 & 0.78 & [5] \\
\hline SHS-60x60x3 & 1.4301 & 2 & 0.70 & 1 & 0.78 & 0.91 & [5] \\
\hline SHS-60x60x3 & 1.4301 & 2 & 0.73 & 1 & 0.82 & 0.95 & [5] \\
\hline SHS-100x100x3 & 1.4301 & 4 & 0.79 & 4 & 0.82 & -- & {$[5]$} \\
\hline SHS-100x100x3 & 1.4301 & 4 & 0.80 & 4 & 0.83 & -- & [5] \\
\hline RHS-60x40x3 & 1.4301 & 1 & 0.54 & 1 & 0.54 & 0.70 & [5] \\
\hline RHS-60x40x3 & 1.4301 & 1 & 0.54 & 1 & 0.54 & 0.70 & [5] \\
\hline RHS-40x60x3 & 1.4301 & 1 & 1.03 & 1 & 1.03 & 0.85 & [5] \\
\hline RHS-40x60×3 & 1.4301 & 1 & 1.07 & 1 & 1.07 & 0.75 & [5] \\
\hline H-200x140x6x6 & 1.4162 & 4 & 0.66 & 4 & 0.67 & -- & [5] \\
\hline H-200x140x8x6 & 1.4162 & 4 & 0.64 & 3 & 0.64 & -- & [5] \\
\hline H-200x140x10x8 & 1.4162 & 1 & 0.80 & 1 & 0.80 & 0.92 & [5] \\
\hline $\mathrm{H}-200 \times 140 \times 12 \times 8$ & 1.4162 & 1 & 0.72 & 1 & 0.72 & 0.92 & [5] \\
\hline$H-200 \times 140 \times 6 \times 6$ & 1.4162 & 4 & 0.55 & 4 & 0.56 & -- & [5] \\
\hline H-200x140x8x6 & 1.4162 & 4 & 0.57 & 3 & 0.57 & -- & [5] \\
\hline $\mathrm{H}-200 \times 140 \times 10 \times 8$ & 1.4162 & 1 & 0.85 & 1 & 0.85 & 0.83 & [5] \\
\hline $\mathrm{H}-200 \times 140 \times 12 \times 8$ & 1.4162 & 1 & 0.81 & 1 & 0.81 & 0.89 & [5] \\
\hline H-100x100x $8 \times 8$ & 1.4301 & 1 & 0.89 & 1 & 0.89 & 1.14 & {$[10,21]$} \\
\hline H-100x100x8x8 & 1.4301 & \multicolumn{4}{|c|}{ Failed by early lateral torsional buckling } & & {$[10,21]$} \\
\hline RHS-60x40x4 & S355 & 1 & 0.87 & -- & -- & 0.96 & [4] \\
\hline RHS-60x40x4 & $\mathrm{S} 235$ & 1 & 0.70 & -- & -- & 0.85 & [4] \\
\hline RHS-60x40x4 & $\mathrm{S} 235$ & 1 & 0.70 & -- & -- & 0.84 & [4] \\
\hline RHS-60x40x4 & $\mathrm{S} 355$ & 1 & 0.86 & -- & -- & 0.95 & {$[4]$} \\
\hline SHS-40x40x4 & S355 & 1 & 0.85 & -- & -- & 0.94 & [4] \\
\hline SHS- $40 \times 40 \times 4$ & $\mathrm{~S} 235$ & 1 & 0.76 & -- & -- & 0.90 & [4] \\
\hline SHS-40x40x4 & S355 & 1 & 0.87 & -- & -- & 0.96 & [4] \\
\hline SHS- $40 \times 40 \times 4$ & $\mathrm{~S} 235$ & 1 & 0.75 & -- & -- & 0.89 & [4] \\
\hline SHS-40x40x3 & S355 & 1 & 0.84 & -- & -- & 0.93 & [4] \\
\hline SHS-40x40x3 & $\mathrm{S} 235$ & 1 & 0.77 & -- & -- & 0.93 & [4] \\
\hline SHS-40x40x3 & S355 & 1 & 0.83 & -- & -- & 0.91 & [4] \\
\hline SHS-40x40x3 & $\mathrm{S} 235$ & 1 & 0.79 & -- & -- & 0.95 & [4] \\
\hline H-Beam 1 & S275 & 1 & 0.78 & -- & -- & 0.88 & [23] \\
\hline H-Beam 2 & $\mathrm{~S} 275$ & 1 & 0.81 & -- & -- & 0.92 & [23] \\
\hline H-Beam 3 & $\mathrm{~S} 275$ & 1 & 0.85 & -- & -- & 0.95 & [23] \\
\hline H-Beam 4 & $\mathrm{~S} 275$ & 1 & 0.84 & -- & -- & 0.95 & [23] \\
\hline
\end{tabular}




\begin{tabular}{lccccccc} 
H-Beam 5 & S275 & 1 & 0.88 & -- & -- & 0.96 & {$[23]$} \\
H-Beam 6 & S235 & 1 & 0.95 & -- & -- & 1.01 & {$[22]$} \\
H-Beam 7 & S235 & 1 & 0.99 & -- & -- & 1.13 & {$[24]$} \\
\hline \hline & Mean & 0.77 & & 0.78 & 0.90 & \\
& & COV. & 0.163 & & 0.191 & 0.108 & \\
\hline
\end{tabular}

From Table 9 the CSM is the most accurate design approach for indeterminate beams, even considering it is not applicable to all of the analyzed beams. However the EN1993-1-4 [2] expressions, with the revised classification limits and allowing for plastic design, do also provide good resistance predictions while maintaining a simple design process.

Finally, the predicted collapse loads calculated by classic plastic design $F_{\text {coll }}$ have been normalized by the experimental ultimate loads for all the test results, regardless of the crosssectional classification, and are shown in Figure 17. The cross-sectional slenderness is determined from $\bar{\lambda}_{\mathrm{p}}=\sqrt{\sigma_{0.2} / \sigma_{\mathrm{cr}}}$, where $\sigma_{\mathrm{cr}}$ is the critical buckling stress, calculated according to EN1993-1-5 [26] for the most slender plate element in the cross-section.

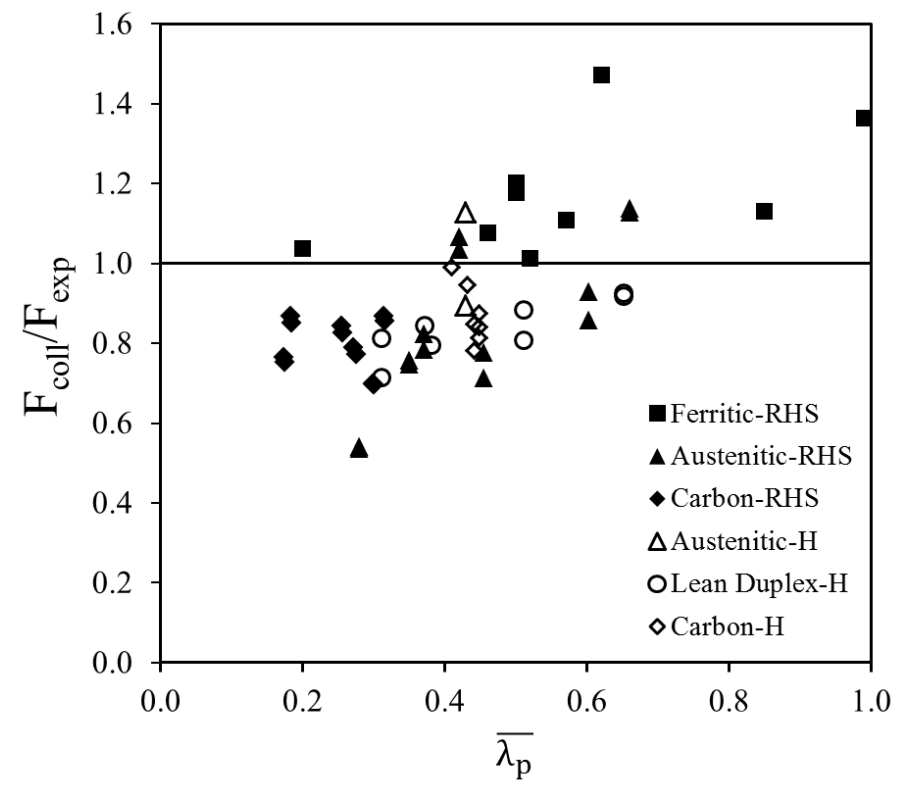

Figure 17. Assessment of the classic plastic design method.

The bending capacity of the most slender beams is overpredicted when plastic design is considered, although the resistance predictions get more accurate for cross-sections with an 
intermediate slenderness. For the stockiest cross-sections, where the strain hardening is more influential, the use of an elastic-perfectly plastic material model results in overconservative predictions. This behaviour is observed for all of the considered materials, although a larger more extensive database is required for more general conclusions.

The assessment of the considered design methods for the different steel and cross-sectional types is summarized in Table 10, with the conclusions in line with those made for Table 9. However, it should be noted that the application of plastic design to ferritic cross-sections requires further research, with the Class 1 limits having been found to be overly for both classifications considered in this paper.

Table 10. Assessment of the design methods allowing plastic design.

\begin{tabular}{lccc}
\hline \hline $\begin{array}{c}\text { Material and } \\
\text { cross-section }\end{array}$ & $\mathrm{F}_{\mathrm{uEN}} / \mathrm{F}_{\mathrm{u}}$ & $\mathrm{F}_{\mathrm{urENev}} / \mathrm{F}_{\mathrm{u}}$ & $\mathrm{F}_{\mathrm{uCSM}} / \mathrm{F}_{\mathrm{u}}$ \\
\hline \hline Ferritic RHS & 0.87 & 1.11 & 1.06 \\
Austenitic RHS & 0.72 & 0.79 & 0.82 \\
Carbon Steel RHS & 0.80 & -- & 0.92 \\
Austenitic H & 0.89 & 0.89 & 1.14 \\
Lean duplex H & 0.70 & 0.70 & 0.89 \\
Carbon Steel H & 0.87 & -- & 0.97 \\
\hline \multicolumn{1}{c}{ Mean } & 0.79 & 0.86 & 0.92 \\
COV. & 0.277 & 0.277 & 0.116 \\
\hline \hline
\end{tabular}

\section{CONCLUSIONS}

A comprehensive experimental programme on ferritic stainless steel grade EN1.4003 coldformed RHS and SHS beams has been presented in this paper, with five different cross-sections tested. Simply supported and continuous beam tests over two spans were conducted after characterizing the material behaviour with flat and corner coupon tensile tests. The test results reported by other authors in different stainless steel grades and carbon steel have also been included in the analysis. 
Four three-point and eight four-point bending tests were conducted for the determination of the bending resistance of the cross-sections subjected to different moment distributions, for both the major and minor axes for RHS. Experimental results have been used to assess the adequacy of the cross-sectional classification slenderness limits currently codified in EN1993-1-4 [2] and those proposed by Gardner and Theofanous [14] and for determining the most appropriate design approach to predict the bending capacity of ferritic RHS and SHS. The four-point bending test results demonstrated that the revised cross-sectional classification limits given in [14] for Class 3 and Class 2 are more accurate than those coded in [2], which provide safe but overly conservative results. Additionally, it has been concluded that the definition of the Class 1 limit needs to be reconsidered for ferritic stainless steel elements since unsafe predictions are provided by both.

The interaction of the local transverse force and bending moment was investigated through the three-point bending tests, and it was concluded that the interaction expression given in EN1993-1-3 [19] provides excellent results using the expression proposed by Bock et al. [20] for the calculation of the web crippling resistance, while the EN1993-1-3 [19] approach is too conservative.

A total of nine continuous beams were also tested over a two span configuration in order to investigate their redistribution capacity and to assess the applicability of the classical plastic design to ferritic stainless steel structures. The most appropriate prediction of the ultimate resistance for ferritic RHS continuous beams using elastic calculations, from EN1993-1-4 [2], is obtained for the revised cross-sectional limits proposed in [14]. However the applicability of plastic design to ferritic RHS elements could not be studied as none of the cross-sections were experimentally classified as Class 1 . The study of the applicability of plastic analysis for ferritic stainless steel indeterminate structures is therefore still open. 
When different stainless steel grades are considered, the CSM provides the best prediction of the collapse loads for indeterminate beams, and the most accurate ultimate capacity predictions according to classical plastic design and EN1993-1-4 [2] approach are obtained for the revised cross-sectional classification limits. Further research is necessary to extend this study to stockier ferritic cross-sections through additional experimental tests and parametric studies along with a statistical validation of the proposed expressions.

\section{ACKNOWLEDGEMENTS}

This experimental programme was possible thanks to the funding from the Ministerio de Economía y Competitividad (Spain) under the Project BIA 2012-36373. The first author would like to acknowledge the financial support provided by the Secretaria d'Universitats i de Recerca del Departament d'Economia i Coneixement de la Generalitat de Catalunya i del Fons Social Europeu through FI-DGR 2014. The authors would also like to mention Acerinox for their support and Tomàs Garcia for his contribution to the experimental investigations.

\section{REFERENCES}

[1] Cashell KA and Baddoo NR. Ferritic stainless steels in structural applications. Thin-Walled Structures 83 (2014), 169-181.

[2] EN1993-1-4. Eurocode 3: design of steel structures - Part 1-4: general rules supplementary rules for stainless steels. Brussels: European Committee for Standardization (CEN), 2006.

[3] EN1993-1-1. Eurocode 3: design of steel structures - Part 1-1: general rules and rules for building. Brussels: European Committee for Standardization (CEN), 2005. 
[4] Gardner L, Wang FC, and Liew A. Influence of strain hardening on the behaviour and design of steel structures. International Journal of Structural Stability and Dynamics 11(5) (2011), 855-875.

[5] Theofanous M, Saliba N, Zhao O, and Gardner L. Ultimate response of stainless steel continuous beams. Thin-Walled Structures 83 (2014), 115-127.

[6] Bock M, Arrayago I, Real E. Experiments on cold-formed ferritic stainless steel slender sections. Journal of Constructional Steel Research 109 (2015), 13-23.

[7] EN ISO6892-1. Metallic materials - Tensile testing - Part 1: Method of test at room temperature. Brussels: European Committee for Standardization (CEN); 2009.

[8] Cruise RB, Gardner L. Strength enhancements induced during cold forming of stainless steel sections. Journal of Constructional Steel Research 64(11) (2008), 1310-1316.

[9] EN10088-4. Stainless steels: Part 4: Technical delivery conditions for sheet/plate and strip of corrosion resisting steels for general purposes. Brussels; European Committee for Standardization (CEN), 2009.

[10] Mirambell E and Real E. On the calculation of deflections in structural stainless steel beams: an experimental and numerical investigation. Journal of Constructional Steel Research 54 (2000), 109-133.

[11] Real E, Arrayago I, Mirambell E and Westeel R. Comparative study of analytical expressions for the modelling of stainless steel behaviour. Thin-Walled Structures 83 (2014), 211.

[12] Arrayago I, Real E and Gardner L. Description of stress-strain curves for stainless steel alloys. Materials and Design 87 (2015), 540-552. 
[13] Hradil P and Talja A. Investigating the role of gradual yielding in stainless steel columns and beams by virtual testing. Proceedings of The Fifth International Conference on Structural Engineering, Mechanics and Computation. Cape Town, South Africa, (2013),1459-1464.

[14] Gardner L and Thoufanous M. Discrete and continuous treatment of local buckling in stainless steel elements. Journal of Constructional Steel Research 64 (2008), 1207-1216.

[15] Rasmussen KJR and Hankock GJ. Design of cold formed stainless steel structural members. II: Beams. Journal of Structural Engineering, ASCE. 119(8) (1993), 2368-2386.

[16] Afshan S and Gardner L. Experimental study of cold-formed ferritic stainless steel hollow sections. Journal of Structural Engineering, ASCE 139(5) (2013), 717-728.

[17] Afshan S and Gardner L. The continuous strength method for structural stainless steel design. Thin-Walled Structures 68 (2013), 42-49.

[18] Bock M, Gardner L and Real E. Material and local buckling response of cold-formed ferritic stainless steel sections. Thin-Walled Structures 89 (2015), 131-141.

[19] EN 1993-1-3. Eurocode 3: design of steel structures - Part 1-3: general rules - General rules. Supplementary rules for cold formed members and sheeting. European Committee for Standardization (CEN), Brussels 2006.

[20] Bock M, Arrayago I, Real E, Mirambell E. Study of web crippling in ferritic stainless steel cold formed sections. Thin-Walled Structures 69 (2013), 29-44.

[21] Real E and Mirambell E. Flexural behaviour of stainless steel beams. Engineering Structures 28(6) (2005), 926-934.

[22] Yang CH, Beedle LS and Johnston BG. Residual stress and the yield strength of steel beams. The Welding Journal 31(4) (1952), 205-229. 
[23] Popov EP and Willis JA. Plastic design of cover plated continuous beams. Journal of Engineering Mechanics ASCE 84(1) (1957), 1495-1515.

[24] Driscoll GC and Beedle LS. The plastic behaviour of structural members and frames. The Welding Journal 36(6) (1957), 275-s.

[25] Gardner L. The Continuous Strength Method. Proceedings of the Institution of Civil Engineers - Structures and Buildings 161(3) (2008), 127-133.

[26] European Committee for Standardization (CEN). (2006b). "Design of steel structures: Part 1-5: Plated structural elements.” Eurocode 3, EN 1993-1- 5, Brussels, Belgium. 